Research Article

\title{
The Dependence of Northwest Pacific Tropical Cyclone Intensification Rates on Environmental Factors
}

\author{
Xinyan Lyu, ${ }^{1,2}$ Xuguang Wang $\mathbb{D}^{1},{ }^{1}$ and Lance $M$. Leslie $\mathbb{D}^{1,3}$ \\ ${ }^{1}$ School of Meteorology, University of Oklahoma, Norman, Oklahoma 73072, USA \\ ${ }^{2}$ National Meteorological Center, Beijing 100081, China \\ ${ }^{3}$ School of Mathematical and Physical Sciences, University of Technology Sydney, Sydney, Australia \\ Correspondence should be addressed to Xuguang Wang; xuguang.wang@ou.edu
}

Received 19 June 2019; Revised 18 September 2019; Accepted 22 October 2019; Published 7 December 2019

Academic Editor: Budong Qian

Copyright ( $\odot 2019$ Xinyan Lyu et al. This is an open access article distributed under the Creative Commons Attribution License, which permits unrestricted use, distribution, and reproduction in any medium, provided the original work is properly cited.

\begin{abstract}
The Northwest Pacific tropical cyclone (TC) intensification is classified into rapid intensification (RI), normal intensification (NI), and slow intensification (SI) categories. The initial location and intensity, the preceding intensity change, the motion direction, the occurrence month, and the intensification duration time are all found to differ for RI cases compared with NI and SI cases. The dependence of RI, NI, and SI on environmental conditions is further examined statistically by using the intensification rates of named TCs, for the 21-year period 1995-2015, obtained from JTWC best track data, and the environmental conditions derived from the ERA-Interim reanalysis data and GODAS high-resolution global ocean analysis data. It was found that deep-layer and upper-mid vertical wind shear (VWS), upper-level outflow, sea surface temperature (SST), and ocean heat content (OHC) are statistically different among RI, NI, and SI both before and during intensification. RI is enhanced by weaker and decreasing VWS, warmer oceans, and stronger and increasing outflow. In contrast, SI typically occurs with larger and increasing VWS, cooler oceans, and weaker, static outflow. The impacts of low-level VWS and net moisture inflow are only significantly different between RI and SI and between NI and SI, but not between RI and NI. Another key finding is that increased upper-level outflow and decreased VWS are important precursors and hence are possible predictors, of RI onset. The direction of upper-level outflow affects TC intensification, with NW and NE outflow being more favorable for TC RI than SE and SW outflow.
\end{abstract}

\section{Introduction}

The operational prediction of tropical cyclone (TC) intensity change remains a major challenge. Operational forecasts often are required to distinguish rapid intensification (RI) and slow intensification (SI) from normal intensification (NI) [1-3]. However, during RI, the forecast intensification rate (IR) typically is far lower than the observed IR, whereas it is much higher than the observed IR in the SI cases $[3,4]$. In some operational TC forecast centers (Figure 1), when forecasters are unsure of how rapidly TCs will intensify, the default forecast issued is that the TC will undergo NI [3]. The difficulty of distinguishing between RI, NI, and SI during the forecast is due partly to the challenge of quantifying the relationship between the predictors and the IR. Most previous studies focused solely on comparing environmental conditions between RI and
non-RI cases. Some of these studies revealed statistically significant differences in the environmental conditions between RI and non-RI cases [5, 6]. However, in these studies, the non-RI category does not distinguish between NI, SI, and weakening storms. Hendricks et al. [7] classified the intensification into two categories: rapidly intensifying and intensifying and showed that the environmental conditions, including sea surface temperature (SST), and other environmental parameters associated with these two categories are similar. The present study further explores the relationship between environmental conditions and TC IR and, in contrast to previous studies, also classifies the IR into the three categories of RI, NI, and SI. The main motivation for this study is toward addressing the need for, and challenges of, distinguishing between the various intensification phases present during the operational forecast period. 


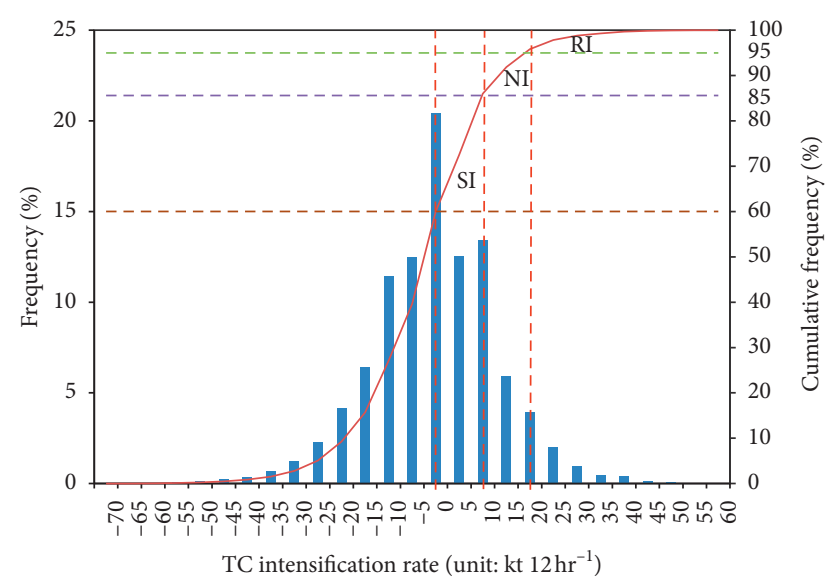

FIgURE 1: Frequency distribution and cumulative frequency distribution of the $12 \mathrm{hr}$ intensity changes of all TCs in the 1995-2015 in Northwest Pacific basin (10156 cases).

Most of the earlier studies have focused on hurricanes in the North Atlantic or the East Pacific basins $[5,6,8]$. However, this study concentrates on TCs over the Northwest Pacific Basin (NWP). The NWP is controlled by the monsoon background, with about $70 \%$ of all TC genesis occurring in the monsoon trough $[9,10]$. This is very different from other ocean basins. For example, in the East Pacific and North Atlantic basins, the main genesis source is African Easterly Waves [11]. Hence, the relative importance of the individual predictors for TC intensification is likely to be different in various basins $[6,12]$. Rios-Berrios and Torn [13] also suggested it is problematic to consider all basins jointly, because the relative importance of environmental conditions for TC intensity change depends on the ocean basin.

The present study seeks to address an important, but as yet unanswered, question: "Do significant differences in environmental factors, including atmospheric conditions and ocean heat conditions, exist between rapidly, normally, and slowly intensifying TCs in the NWP?" In this study, a range of environmental factors is examined, including vertical wind shear (deep-layer, upper-mid, mid-low, and low-level), net moisture inflow, upper-level outflow (strength and direction), and ocean heat conditions (both SST and ocean heat content (OHC)). Earlier, limited studies of the NWP TC basin either examined different TC categories [14] or focused only on one environmental factor [12].

Specifically, the following environmental factors and their relationships with RI, NI, and SI are assessed. Environmental vertical wind shear (VWS) is one of the most important factors influencing TC intensity change, and it is widely accepted that strong VWS generally inhibits TC intensification $[5,7,12,15-18]$. VWS also provides probability estimates of RI in dynamical-statistical models $[5,6,16,19]$ and can assist in determining if, and when, RI will occur [20-22]. The deep layer, $200-850 \mathrm{hPa}$ VWS, is commonly used, whereas other studies showed that the VWS at different levels can also impact TC intensity change $[12,23-25]$. Hence, it is too simplistic to assess the impact of VWS on TC intensity change by using a VWS calculated from just two levels [26-29]. In this study, the VWS between different vertical levels are used to analyze the impact of VWS on the three TC intensification rates, RI, NI, and SI.

Environmental moisture is also suggested as a possible important factor for TC intensification. Both theoretical and modeling studies showed that high environmental moisture favors TC intensification $[30,31]$, whereas dry air intrusion can cause TC decay [21, 32]. The environmental relative humidity $(\mathrm{RH})$ of the lower and middle troposphere is higher for RI cases than non-RI cases [5-7]. However, other studies suggested that moisture might have a negative or no significant impact on TC intensification [33-35]. Therefore, the impact of environmental moisture on TC IR requires further, more detailed, examination. In this study, the impact of environmental moisture on the TC IR is studied by using the low-level to mid-level net moisture inflow, defined as the sum of net moisture inflow from all sides of a box surrounding the TC center and extending from the surface to $500 \mathrm{hPa}$. This quantity is used to represent the total lowlevel to mid-level moisture transport from the environment into the TC core.

Due to the asymmetric structure [36, 37], low Richardson number [38, 39], and weaker inertial instability [40-43] of the TC upper-level outflow, the outflow can easily interact with the upper-level larger-scale environment and the inner-core of a TC, thereby playing a mediating role between the environment and the storm core [41]. As such, it can affect the secondary circulation and, consequently, the TC intensity [37, 41, 43-49]. The upper-level radial outflow is much stronger $[6,37,43]$ and usually is more concentrated close to the TC center for intensifying cases than for nonintensifying cases [43]. In addition, TC intensification is associated with the multiple upper-level outflow channels, and TCs usually weaken when one of the efficient upperlevel outflow channels is cut off $[44,50-53]$. Kaplan and DeMaria [5] and Shu et al. [14] noted that upper-tropospheric flows for RI cases are more easterly than for non-RI cases. Rappin et al. [41] showed that the ventilation of outflow in north and northeast directions minimizes the hurricane energy expenditure, leading to larger intensification rates. Hence, the direction of TC outflow possibly modifies the effect of outflow on TC intensity change. In this study, the significant differences in the impacts of both the strength and direction of outflow are examined, for all three different TC intensification categories. As far as the authors are aware, this relationship between outflow direction and TC IR has not previously been statistically analyzed.

The effect of the ocean heat conditions on TC intensity change has been addressed for decades [54-57]. SST is widely known to affect TC intensification $[5,6,58] . \mathrm{Nu}^{-}$ merous supporting case studies exist [21, 59-61]. Statistical analyses $[8,12]$ showed that TCs typically intensify (weaken) over warmer (colder) ocean eddy regions with higher (lower) SST. Some studies have shown that the OHC, measured from the surface to the depth of the $26^{\circ} \mathrm{C}$ isotherm, is important for TC intensity change [59], and that SST alone is not always a good measure of the total heat content that affects TC intensity change [62]. This hypothesis is further supported by studies showing that the use of OHC can help 
reduce TC intensity forecast errors in the statistical model, SHIPS $[63,64]$. In the present study, both SST and OHC are used to determine the impact of ocean heat conditions on RI, NI, and SI.

In summary, the main question that needs to be addressed in this study is whether there are significant differences in large-scale atmospheric environmental conditions, such as VWS at different vertical levels, net environmental moisture inflow, strength and direction of upperlevel outflow, and ocean heat conditions (SST and OHC) between RI, NI, and SI, for NWP TCs. Additionally, a unique aspect of this study is the use of a relatively long period of data to derive statistically robust results, as all named NWP TCs during the 21-year period from 1995 to 2015 are included. The findings from this study are relevant to improving TC forecast skill and to increasing our understanding of the TC intensification processes.

Section 2 describes the data and provides definitions of the environmental conditions. Section 3 defines the RI, NI, and SI categories and shows the distribution of TC intensity changes in the NWP basin, and Section 4 describes and discusses the main results. Finally, Section 5 summarizes the findings of this study.

\section{Data and Methodology}

2.1. Data. The Joint Typhoon Warning Center (JTWC) best track data, including the TC center position and maximum $1 \mathrm{~min}$ mean sustained $10 \mathrm{~m}$ wind speed $\left(V_{\max }\right)$, at $6 \mathrm{~h}$ intervals for all named TCs over the NWP basin from 1995 to 2015, were used to calculate TC intensity change and to define the TC environment.

The 6-hourly wind and specific humidity fields and SST data from 1995 to 2015 are from the European Center for Medium-Range Weather Forecasts (ECMWF) interim reanalysis website (https://www.ecmwf.int/en/forecasts/ datasets/reanalysis-datasets/era-interim) [65]. The same ECMWF reanalysis data were widely used in published statistical studies to investigate the relationship between the environmental conditions and the tropical cyclone intensity change (e.g., $[25,66])$. Schenkel and Hart show that for the ECMWF interim reanalysis, most of the TC position errors are less than $150 \mathrm{~km}$ in the Northwest Pacific basin [67]. The study of Hodges et al. showed that for the ECMWF interim reanalysis [68], the majority of the TCs in the reanalysis have a mean position difference from the best track that is less than $2^{\circ}(\sim 220 \mathrm{~km})$. They also showed that the peak of the position error distribution is at about $110 \mathrm{~km}$. Hence, most of the TC position errors in the ECMWF reanalysis are less than $110 \mathrm{~km}$ [68]. In the studies of Schenkel and Hart [67] and Hodges et al. [68], the earlier ECMWF interim reanalysis was evaluated. In our study, we used the most recent 20-year ECMWF reanalysis (1995-2015). Because this period is more recent and therefore the quality of the ECMWF interim reanalysis data should be improved, the TC position errors of the ECMWF reanalysis in our study should be smaller than that of Schenkel and Hart [67] and Hodges et al. [68]. In addition, the horizontal grid spacing of the ECMWF interim reanalysis is $0.5^{\circ}$ longitude $\times 0.5^{\circ}$ latitude. In other words, the smallest resolvable scale is about $\sim 100 \mathrm{~km}$, comparable to the peak position error in Hodges et al.'s study [68]. Moreover, the computational domain which is used to calculate the environmental conditions in this study is relatively large compared to the TC position error $(\sim 110 \mathrm{~km})$. Based on all of the above, the TC position error in the ECMWF interim analysis is not expected to impact our results. So the reanalysis data are used to calculate different level VWS, upper-level outflow, net moisture inflow, and SST around the TC center, during the intensification period.

To study the impact of $\mathrm{OHC}$, the high-resolution global ocean analysis sea temperature data (34 levels up to $5000 \mathrm{~m}$, $12 \mathrm{~km}$ grid spacing) were provided by U.S. GODAE (U.S. Global Ocean Data Assimilation Experiment) (http:// usgodae.org/). GODAE was shown by early studies to provide high-quality ocean analysis data [69] and was used to analyze the upper-ocean heat condition (e.g., [70]). These data are used to calculate the $\mathrm{OHC}$ around the $\mathrm{TC}$ center in this study. Although the GODAE data have high spatial resolution, they are only available after 2007 . Therefore, only a 9-year worth of data (2007-2015) were used. Given the statistical relationship between intensification rates and other environmental variables was studied using 20-year data, caution should be taken to intercompare the OHC impact with other environmental variables.

\subsection{Definitions of TC Environmental Conditions}

2.2.1. Vertical Wind Shear. The environmental vertical wind shear, VWS, is defined as the wind vector difference between two levels as shown in the following equation:

$$
\mathrm{VWS}_{\text {lev1-lev2 }}=\left|V_{\text {lev1 }}-V_{\text {lev2 }}\right| \text {, }
$$

where the $V_{\text {lev1 }}$ and $V_{\text {lev2 }}$ variables are annular-averaged horizontal wind vector at level 1 and level 2. In this calculation, the annular is between 200 and $800 \mathrm{~km}$ from the storm center. Therefore, the inner-core region of the storm is removed or filtered when the environmental shear is calculated. The subscripts "lev1" and "lev2" indicate two pressure levels. This method of defining and calculating the vertical wind shear follows the studies $[14,19]$. We calculate 4 types of wind shear $\mathrm{VWS}_{200-850}, \mathrm{VWS}_{200-500}, \mathrm{VWS}_{500-850}$, and $\mathrm{VWS}_{850-1000}$ as follows. The deep-layer shear $\mathrm{VWS}_{200-850}$ is calculated. It is commonly used to diagnose the relationship between TCs intensity change and environmental vertical wind shear (e.g., [18, 19]). $850 \mathrm{hPa}$, $500 \mathrm{hPa}$, and $200 \mathrm{hPa}$ are commonly used to analyze the lowlevel, mid-level, and upper-level circulations of tropical cyclone. Therefore, in addition to $\mathrm{VWS}_{200-850}, \mathrm{VWS}_{200-500}$ and $\mathrm{VWS}_{500-850}$ are also used because early studies suggest these shears can also impact TC intensity change [19, 71]. Moreover, both the statistical and idealized simulation studies found that the low-level shear could have a negative effect on TC intensification $[12,24]$. In particular, the study by Wang et al. [12] showed that the low-level shear between 850 and $1000 \mathrm{hPa}$ can have a larger negative impact on TC intensity change than VWS at other levels during active seasons. So the low-level shear is also calculated in this study. 
2.2.2. Net Moisture Inflow. The net inflow of environmental moisture is used to assess the impact of environmental moisture on TC intensity change. The net moisture inflow flux is defined as

$$
Q u v=\int_{\text {surface }}^{500 h p a}(q e+q s+q w+q n) \mathrm{d} p,
$$

where $q e, q s, q w$, and $q n$ are the net moisture inflows from the eastern, southern, western, and northern boundaries, respectively, of a $8^{\circ} \times 8^{\circ}$ latitude-longitude box around the TC center. Hence, Quv is the total net moisture transport to the TC core from the surface to $500 \mathrm{hPa}$. The units of Quv are $\mathrm{kg} \mathrm{m}^{-2} \mathrm{~s}^{-1}$. In equation (2),

$$
\begin{aligned}
& q e=-\frac{1}{g} q u, \\
& q s=\frac{1}{g} q v, \\
& q w=\frac{1}{g} q u, \\
& q n=-\frac{1}{g} q v,
\end{aligned}
$$

where $q$ is the specific humidity, $u$ and $v$ are the zonal wind and meridional wind components, respectively, and $g$ is $9.8 \mathrm{~m} \mathrm{~s}^{-2}$.

2.2.3. Upper-Level Outflow. The strongest TC outflow is, on average, concentrated at about $200 \mathrm{hPa}$ and around $500 \mathrm{~km}$ from the TC center $[38,43]$. In this study,

$$
\oiint_{D} \nabla . F \mathrm{~d} S=\oint F . n \mathrm{~d} s,
$$

where from Green's law, the upper-level outflow strength is defined as the area-averaged divergence over the $8^{\circ} \times 8^{\circ}$ latitude-longitude box around the TC center, at $200 \mathrm{hPa}$.

For simplicity, the impact of outflow direction on IR is investigated only for cases with a single-outflow channel. A single-outflow channel is defined as occurring when the quadrant-mean wind within $500 \mathrm{~km}$ from the storm center is outward and greater than $6 \mathrm{~m} \mathrm{~s}^{-1}$. In the Northern Hemisphere, the anticyclonic outflow of TCs mainly has four radial directions: northwest (NW), northeast (NE), southwest (SW), and southeast (SE). Therefore, in this study, only the NW, NE, SW, and SE quadrants are considered.

2.2.4. SST and OHC. The OHC definition follows Buckley et al. [72] except that we choose the $26^{\circ} \mathrm{C}$ isotherm depth as the integral depth during the vertical integration. This replacement was according to early studies (e.g., [73]) which showed that the TC genesis and/or TC intensity change can be sensitive to the depth of the $26^{\circ} \mathrm{C}$ isotherm. Accordingly, the areal density of the $\mathrm{OHC}$ is defined as

$$
\mathrm{OHC}=\rho c_{p} \int_{h\left(T=26^{\circ} \mathrm{C}\right)}^{0} T(z) \mathrm{d} z,
$$

where $\rho$ is the seawater density, $c_{p}$ is the specific heat of sea water, $h$ is the depth of the $26^{\circ} \mathrm{C}$ sea temperature contour, and $T(z)$ is the sea temperature at the depth $z$. The unit of the areal density of ocean heat content is $\mathrm{kJ} \mathrm{cm}^{-2}$. Hence, OHC is the total ocean heat content per square centimeter, from the depth of the $26^{\circ} \mathrm{C}$ contour sea temperature to the sea surface. In this study, the area-averaged SST and OHC over the $2^{\circ} \times 2^{\circ}$ square box around the TC center is used to calculate the ocean heat conditions.

2.3. Significant Difference Tests. The testing of significant differences between mean values was carried out using a standard bootstrapping method $[74,75]$. This method was used to obtain confidence levels for the differences in the sample means of the various parameters in this study. As an example, it was used to compare the mean intensification rates for RI and SI in deep-layer VWS environments. Here, confidence levels of $90 \%$ and $95 \%$ are used, and the number of resamples in this study is 10,000 . The bootstrap technique was used in early studies by Wang and Bishop [75] and Hamill et al. [76].

\section{Definitions and Distributions of RI, NI, and SI in the NWP Basin}

3.1. Definitions of RI, NI, and SI. The frequency and cumulative frequency distributions of $12 \mathrm{~h}$ intensity changes for all 499 named TCs over the NWP basin during 19952015 are shown in Figure 1. As this study focuses on TC intensification, only intensifying cases are chosen. The IR is classified into 3 categories: rapid intensification (RI), normal intensification (NI), and slow intensification (SI). These are formally defined in Table 1.

Note that in earlier studies, RI is usually defined as the $95^{\text {th }}$ percentile of all $24 \mathrm{~h}$ TC intensity changes, i.e., approximately $30 \mathrm{kt}$ or greater $[5,12,14]$. These previous definitions did not include the $6 \mathrm{~h}$ TC intensity change. As shown later, the average intensification duration time of the continuous RI process found in this study is $18.8 \mathrm{hr}$. Therefore, using a $24 \mathrm{~h}$ period to define the intensification period might also include a weakening phase. Hence, in this study, a $12 \mathrm{~h}$ period is used to define RI. In addition, to ensure the selection of continuously intensifying cases, where no weakening phases are included, the definition of intensification category is also constrained by the $6 \mathrm{~h}$ intensity change. Specifically as shown in Figure 1, RI is defined as a $12 \mathrm{~h}$ intensity change $\geq 20 \mathrm{kt}$ (i.e., the $95^{\text {th }}$ percentage of TC intensity change for $12 \mathrm{hr}$ ) and a $6 \mathrm{~h}$ intensity change $\geq 5 \mathrm{kt}$. NI is defined as a $12 \mathrm{~h}$ intensity change between $10 \mathrm{kt}$ and $20 \mathrm{kt}$ (i.e., between $85^{\text {th }}$ and $95^{\text {th }}$ percentage of TC intensity change for $12 \mathrm{hr}$ ), and a $6 \mathrm{~h}$ intensity change is between 5 and $10 \mathrm{kt}$. SI requires that the $12 \mathrm{~h}$ intensity change must lie between $0 \mathrm{kt}$ and $10 \mathrm{kt}$ (i.e., between $60^{\text {th }}$ and $85^{\text {th }}$ percentage of TC intensity change for $12 \mathrm{hr}$ ), and the $6 \mathrm{~h}$ intensity change between $0 \mathrm{kt}$ and $5 \mathrm{kt}$. Finally, the total numbers of RI, NI, and SI cases examined in this study are 763,1345 , and 1218, respectively. 
Table 1: Definitions and sample sizes of the three intensification categories.

\begin{tabular}{lcccc}
\hline Category & $\Delta V_{\max }^{12 h}$ & $\Delta V_{\max }^{6 h}$ & Num & Percentage \\
\hline SI & $0<\Delta V_{\max }^{12 h}<10 \mathrm{kt}$ & $0 \leq \Delta V_{\max }^{6 h} \leq 5 \mathrm{kt}$ & 1218 \\
NI & $10 \leq \Delta V_{\max }^{12 h}<20 \mathrm{kt}$ & $5<\Delta V_{\max }^{6 h}<10 \mathrm{kt}$ & 1345 & 36.6 \\
RI & $\Delta V_{\max }^{12 h} \geq 20 \mathrm{kt}$ & $\Delta V_{\max }^{6 h} \geq 5 \mathrm{kt}$ & 763 & 40.5 \\
\hline
\end{tabular}

$\Delta V_{\max }^{6 h}$ and $\Delta V_{\max }^{12 h}$ are TC intensity changes for $6 \mathrm{hr}$ and $12 \mathrm{hr}$ periods, respectively.

3.2. Distributions of RI, NI, and SI. In this section, the statistical distribution of RI, NI, and SI with respect to initial location, initial intensity, moving direction, occurrence month, and intensification duration time are discussed. The initial TC center locations and intensities of the three intensity categories are shown in Figure 2. Hereafter, TC intensities are classified into six categories, tropical depression (TD, $10.8 \mathrm{~m} \mathrm{~s}^{-1} \leq V_{\max } \leq 17.1 \mathrm{~m} \mathrm{~s}^{-1}$ ), tropical storm (TS, $17.2 \mathrm{~m} \mathrm{~s}^{-1} \leq V_{\max } \leq 24.4 \mathrm{~m} \mathrm{~s}^{-1}$ ), severe tropical storm (STS, $24.5 \mathrm{~m} \mathrm{~s}^{-1} \leq V_{\max } \leq 32.6 \mathrm{~m} \mathrm{~s}^{-1}$ ), typhoon (TY, $32.7 \mathrm{~m} \mathrm{~s}^{-1}$ $\leq V_{\max } \leq 41.4 \mathrm{~m} \mathrm{~s}^{-1}$ ), strong typhoon (STY, $41.5 \mathrm{~m} \mathrm{~s}^{-1} \leq V_{\max } \leq$ $50.9 \mathrm{~m} \mathrm{~s}^{-1}$ ), and super typhoon (Super TY, $V_{\max } \geq 51 \mathrm{~m} \mathrm{~s}^{-1}$ ) based on the CMA (China Meteorological Administration) criteria of 2006 [77]. Only named TCs are chosen in this study and TDs are not included.

From Figure 2, the TC data reveal that most RI cases occur at latitudes between $10^{\circ} \mathrm{N}$ and $25^{\circ} \mathrm{N}$, whereas most NI cases occur between $5^{\circ} \mathrm{N}$ and $30^{\circ} \mathrm{N}$, and SI cases occur in an even larger area between $5^{\circ} \mathrm{N}$ and $35^{\circ} \mathrm{N}$. RI cases mainly are concentrated east of the Philippines and in the northern South China Sea. For each intensification category, the distribution of initial intensity as a function of TC intensity grade is shown in Figure 3. For RI cases, the initial intensity most frequently falls in the TY grade. For NI and SI cases, the initial intensity most commonly falls in the TS intensity category. The combined frequency of TY, STY, and super TY categories is about $64 \%$ for RI but only around 33\% for both NI and SI. Overall, the initial intensity of the RI cases generally is much greater than that of NI and SI. However, the RI distribution over the TY, STY, and super TY intensities in Figure 3 shows that fewer RI cases are initiated from the STY and super TY intensities than from TYs. This possibly is because TYs are farther from their MPI (maximum potential hurricane intensity [78]) than STYs and super TYs and hence have greater potential to intensify [79].

The frequency distributions of the TC moving directions for the three intensification rate categories (SI, NI, and RI) are shown in Figure 4. Overall, most of the intensification cases (about 75\%) move northwest (including WNW and NNW), whereas only about $16 \%$ and $7 \%$ of the intensification cases move northeast (including NNE and ENE) and west-southwest, and very few cases move southward (including SSE and SSW) or east-southeastward. It is also found that the percentage of west-northwestward motion is higher for RI cases than NI and SI cases, whereas the percentage of north-northwestward moving TCs is lower for RI cases than NI and SI cases. That is, RI cases tend to move WNW more than NI and SI cases.

Most of the RI cases (about 61\%) occur in August, September, and October, with a peak in September (Figure 5), but about $56 \%$ of NI and SI cases occur mainly in July, August, and September, with an earlier peak in August. As expected, very few TC intensification cases occur in January, February, and March.

As shown in Figure 6, the mean intensification duration times for a continuous RI, NI, and SI process are 18.8 hours, 18.3 hours, and 14.6 hours, respectively. About $70 \%$ of the RI and NI cases intensify for 12-18 hours and only about $30 \%$ of the RI and NI cases continue for 24 hours or longer (Figure 6). Very few TCs can intensify rapidly or normally for longer than 36 hours. Most SI cases (about 71\%) intensify only for 12 hours. Overall, RI has the longest intensification period and SI has the shortest. As discussed earlier, these results form the basis to define different intensification categories using the $12 \mathrm{~h}$ period rather than the $24 \mathrm{~h}$ period.

\section{Results of Dependence of IR on Environmental Factors}

Section 3.2 shows the statistical distributions of initial location, initial intensity, moving direction, occurrence month, and the intensification duration time, which are different among the RI, NI and SI cases. This finding warrants an assessment of their dependence on environmental conditions.

As discussed in Section 1, the selection of the environmental conditions is based on factors that are known to strongly influence TC intensity change. The variables selected are deep-layer shear $\mathrm{VWS}_{200-580}$, the upper-mid shear $\mathrm{VWS}_{200-500}$ and mid-low- shear $\mathrm{VWS}_{500-850}$, and low-level shear $\mathrm{VWS}_{850-1000}$, the net environmental moisture inflow, the upper-level outflow, and ocean heat condition (including both SST and OHC).

4.1. Environmental Vertical Wind Shear. Figure 7 shows the VWS before, during, and after the intensification for the three intensification categories. The significant differences of the mean magnitudes between the three intensification categories are tested using a bootstrap technique. Overall, the deep-layer shear and the upper-mid shear are significantly (greater than 95\% confidence level) lower before, during, and after the RI process than the NI and SI processes. This is not the case for the low-level shears. Notably, though not statistically significantly different, the average low-level shear $\mathrm{VWS}_{850-1000}$ is slightly higher for RI than NI. For mid-low $\mathrm{VWS}_{500-850 \text {, }}$ consistent significant differences exist between RI and SI, but the differences between RI and NI are significant only starting 12 hours before the onset of the intensification and during the intensification (greater than 90\% confidence level). These 


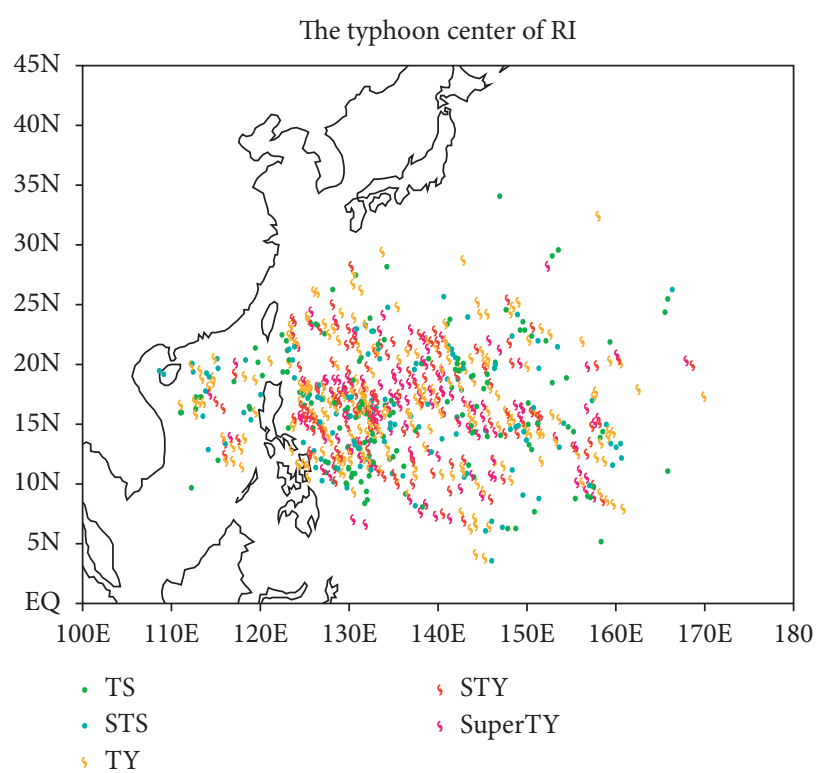

(a)

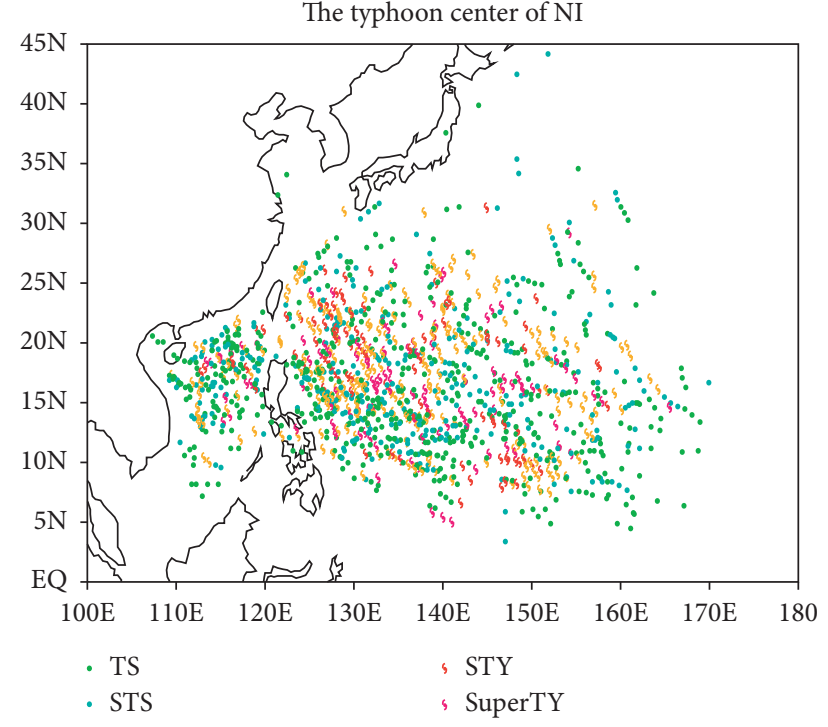

(b)

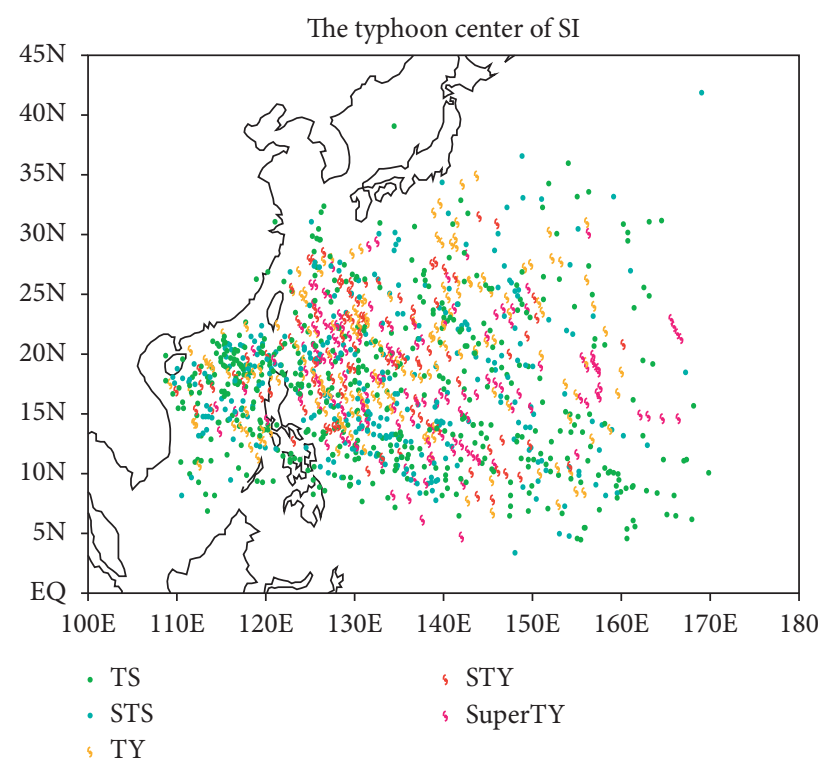

(c)

FIgURE 2: The location distribution of (a) RI cases, (b) NI cases, and (c) SI cases. TC intensities over the Northwest Pacific basin are divided into five categories: tropical storm (TS, $17.2 \mathrm{~m} \mathrm{~s}^{-1} \leq V_{\max } \leq 24.4 \mathrm{~m} \mathrm{~s}^{-1}$ ), severe tropical storm (STS, $24.5 \mathrm{~m} \mathrm{~s}^{-1} \mathrm{~s} \leq V_{\max } \leq$ $32.6 \mathrm{~m} \mathrm{~s}^{-1}$ ), typhoon (TY, $32.7 \mathrm{~m} \mathrm{~s}^{-1} \leq V_{\max } \leq 41.4 \mathrm{~m} \mathrm{~s}^{-1}$ ), strong typhoon (STY, $41.5 \mathrm{~m} \mathrm{~s}^{-1} \leq V_{\max } \leq 50.9 \mathrm{~m} \mathrm{~s}^{-1}$ ), and super typhoon (SuperTY, $V_{\max } \geq 51.0 \mathrm{~m} \mathrm{~s}^{-1}$ ).

results suggest that RI is distinguished from NI and SI primarily by deep-layer, upper-level shear, and mid-low VWS rather than the low-level VWS. In addition, $\mathrm{VWS}_{200-850}, \mathrm{VWS}_{200-500}$, $\mathrm{VWS}_{500-850 \text {, and }} \mathrm{VWS}_{850-1000}$ are also significantly (greater than $90 \%$ confidence level) lower during the NI processes than the SI processes, except during the onset period for $\mathrm{VWS}_{500-850}$. These results show that SI can be distinguished from NI by all VWS.

On average, there are clear decreasing trends of VWS before the onset of RI, except for $\mathrm{VWS}_{850-1000}$ (Figure 7). The decreasing trends commence at least 24 hours prior to the onset of RI. For example, $\mathrm{VWS}_{200-850}$ and $\mathrm{VWS}_{200-500}$ reach their minima at the onset of RI (Figures 7(a) and 7(b)). $\mathrm{VWS}_{500-850}$ decreases to a minimum at 12 hours prior to the onset of RI (Figure 7(c)). Further diagnostics (not shown) reveal that the decreasing trends are accompanied by a reduction in vortex tilt.

For NI and SI, the VWS usually exhibits slight changes before the onset of RI. In particular, $\mathrm{VWS}_{500-850}$ shows a slight increasing trend for NI and SI before the onset of RI. In other words, in addition to the magnitude, the variation of VWS differs for the three TC intensification categories and 


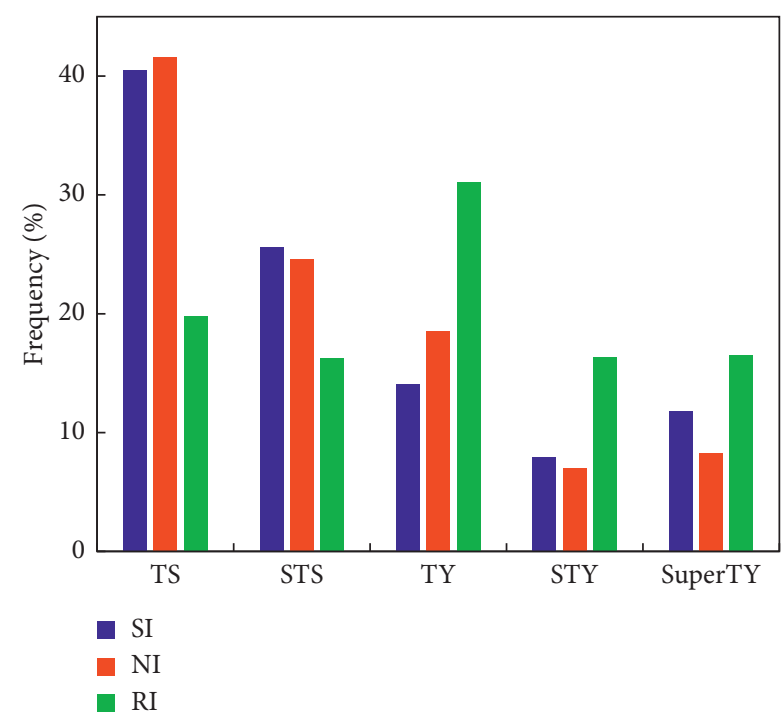

Figure 3: The frequency distribution of the initial intensity of the development in the three intensification categories (RI, NI, and SI) for the period 1995-2015. The definition of TC intensities categories is the same as in Figure 2.

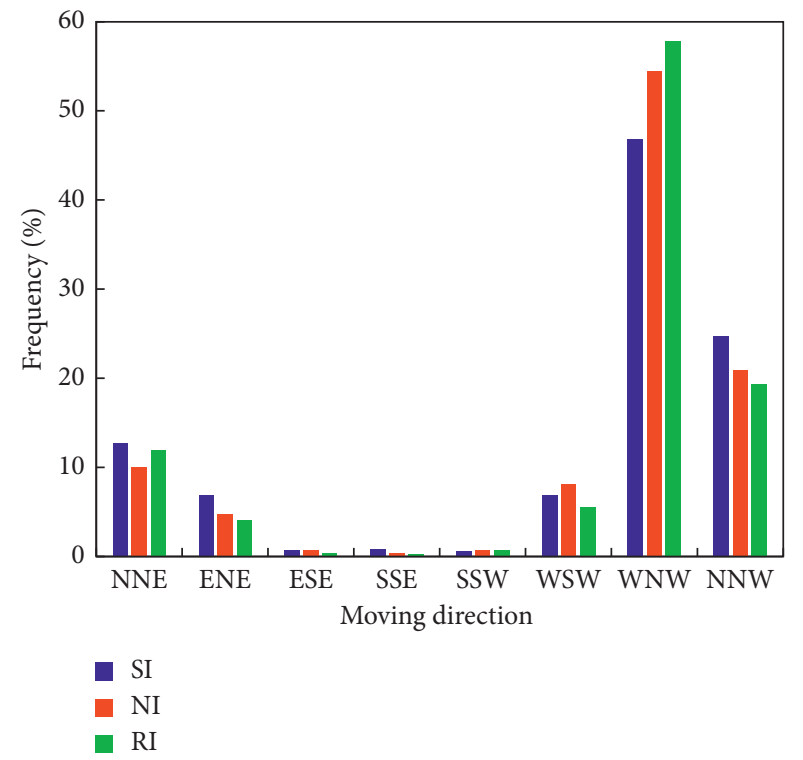

FIGURE 4: The frequency distribution of the moving direction for the three intensification categories (RI, NI, and SI).

therefore can serve as one of the preceding signals for predicting the three intensification categories.

Figure 8 shows the frequency distributions of the three intensification categories as a function of VWS. For $\mathrm{VWS}_{850-1000}$, the percentage peak for all three intensification categories corresponds to the same shear value of 1-2 $\mathrm{m} \mathrm{s}^{-1}$. For shear at other levels, $\mathrm{VWS}_{200-850}, \mathrm{VWS}_{200-500}$, and $\mathrm{VWS}_{500-850}$, the percentage peak of RI corresponds to a smaller VWS shear than NI and SI. Specifically, the percentage peak of RI is at $2-6 \mathrm{~m} \mathrm{~s}^{-1}$ for VWS $200-850,2-4 \mathrm{~m} \mathrm{~s}^{-1}$ for $\mathrm{VWS}_{200-500}$, and about $2-3 \mathrm{~m} \mathrm{~s}^{-1}$ for $\mathrm{VWS}_{500-850}$. In comparison, the percentage peak for NI and SI is about

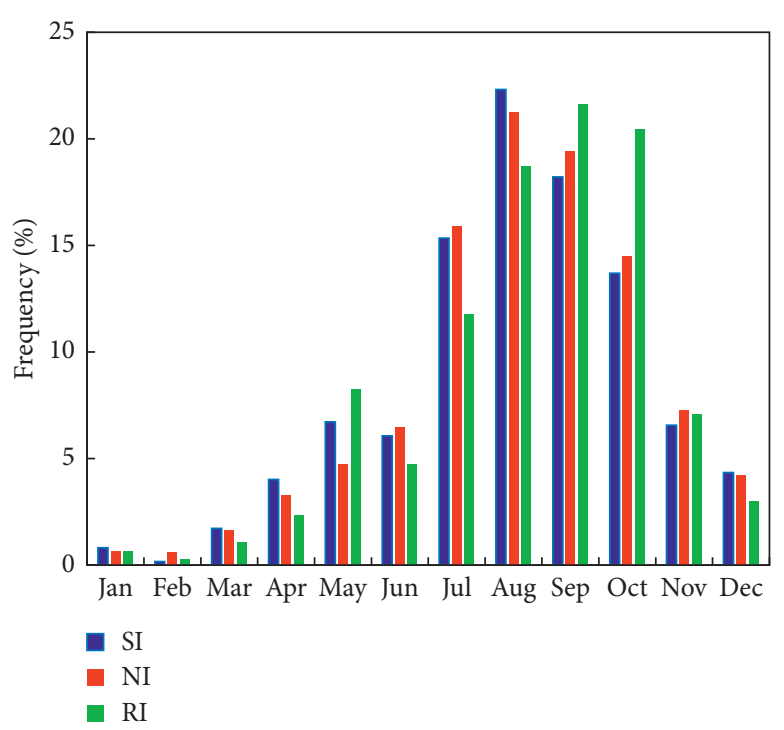

FIGURE 5: The frequency distribution of the initial month of the development for the three intensification categories (RI, NI, and SI) in the Northwest Pacific basin.

2-3 $\mathrm{m} \mathrm{s}^{-1}$ larger than RI. NI and SI are also further compared. For $\mathrm{VWS}_{200-850}$ and $\mathrm{VWS}_{200-500}$, the percentage peak for NI is at a smaller shear than SI, whereas for $\mathrm{VWS}_{500-850}$ and $\mathrm{VWS}_{850-1000}$, they both peak at the same shear. Figure 8 also shows that the shape of the frequency distribution as a function of VWS is different among all three intensification categories. The distribution of RI is sharper and has a higher peak value than NI and SI for $\mathrm{VWS}_{200-850}$, $\mathrm{VWS}_{200-500}$, and $\mathrm{VWS}_{500-850}$, followed by NI. However, for VWS $\mathrm{VS0-1000}$, the distributions among the three categories are in general similar. And for $\mathrm{VWS}_{500-850}$, the percentage peaks of NI and SI are both at 2-3 $\mathrm{m} \mathrm{s}^{-1}$; the differences just are that that the percentage and peak value is slightly higher for NI than SI when $\mathrm{VWS}_{500-850}$ is less than $4 \mathrm{~m} \mathrm{~s}^{-1}$. These results further suggest that deep-layer and upper-mid VWS of the three intensification categories are more significantly different and play more important roles in distinguishing the three intensification categories.

Figure 9 shows the relative occurrence probability of the three intensification categories in each VWS bin. Evidently, the RI occurrence probability decreases linearly with increasing deep-layer VWS $\left(\mathrm{VWS}_{200-850}\right)$ and uppermid VWS $\left(\mathrm{VWS}_{200-500}\right)$. It decreases only marginally with increasing mid-low VWS $\left(\mathrm{VWS}_{200-850}\right)$. RI probability distribution is almost flat when the low-level shear $\left(\mathrm{VWS}_{850-1000}\right)$ is less than $3 \mathrm{~m} \mathrm{~s}^{-1}$ and decreases with increasing low-level shear when $\mathrm{VWS}_{850-1000}$ is greater than $3 \mathrm{~m} \mathrm{~s}^{-1}$. This result suggests that the RI occurrence probability is more sensitive to the deep layer and midupper VWS. The NI mean probability decreases only with increasing $\mathrm{VWS}_{850-1000}$ and with the increasing $\mathrm{VWS}_{500-850}$ if the $\mathrm{VWS}_{500-850}$ is higher than $4 \mathrm{~m} \mathrm{~s}^{-1}$. It is almost flat across the $\mathrm{VWS}_{200-850}$ bin. However, it increases slightly with the increasing $\mathrm{VWS}_{200-500}$. These results indicate that the NI occurrence probability is more sensitive to the upper-mid and low-level VWS than VWS at other levels. 


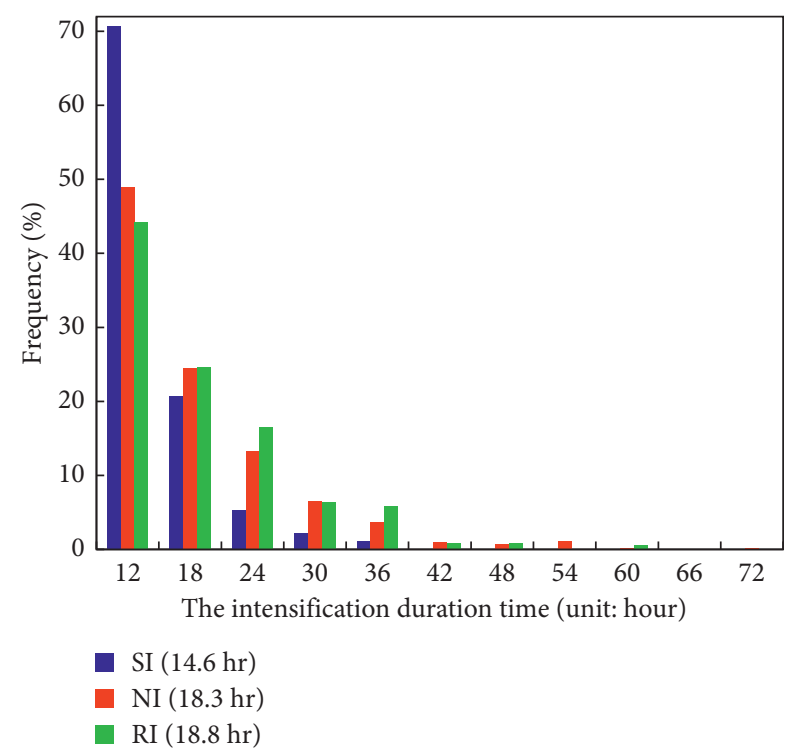

FIgURE 6: The frequency distribution of the intensification duration time of the three intensification categories (RI, NI, and SI) for 1995-2015.

The mean occurrence probability of SI increases especially with an increasing deep-layer and low-level VWS, suggesting its occurrence is more sensitive to the variation of the shear at these levels.

Notably, the error bar range is much larger when VWS is stronger, especially for $\mathrm{VWS}_{200-850}, \mathrm{VWS}_{200-500}$, and $\mathrm{VWS}_{850-1000}$. This result shows that the occurrence probabilities of SI, NI, and RI at large shear are with high uncertainty, suggesting that the probabilities of SI, NI, and RI are more difficult to estimate under strong environmental VWS. These results are consistent with the study of Zhang and Tao [20] that suggests that the larger the VWS, the larger the uncertainty of the predictability of TC intensity. Although the RI occurrence probability shows a decreasing trend for larger shear values for all levels, and the error bars of occurrence probabilities are much larger in low-level than other levels, especially when low-level shear is larger than $4 \mathrm{~ms}^{-1}$. This result together with those from Figures 7 and 8 show that RI, NI, and SI are overall better delineated by the deep-layer and upper-mid shears than the mid-low and lowlevel shears. The role of mid-low and low-level shears on distinguishing the three intensification categories is mixed. These results are in general consistent with earlier studies showing the VWS at different levels can impact TC intensity change differently [12, 23-25].

4.2. Environmental Moisture Condition. Earlier studies on the impact of environmental moisture on the TC intensification produce mixed results $[6,7,33,35]$. This study reexamines the impact of the net environmental moisture in distinguishing RI, NI, and SI. The net moisture inflow (Quv) which measures the moisture transport from the environment to the TC core is used. For each intensification category (SI, NI, and RI), the net moisture inflow changes before and during the intensification are shown in
Figure 10(a). The net moisture inflow apparently increases before, during, and after the RI and NI processes. The increasing rate of the net moisture inflow is much smaller for SI. On average, the net moisture inflow is slightly higher for RI followed by NI and then SI. The difference in the net moisture inflow between SI and RI (NI) is significant at the $90 \%$ level just after the onset of the intensification. However, the difference in net moisture inflow between RI and NI is not statistically significant.

Figure 10(b) shows the percentage distribution of the three intensification categories as a function of net moisture inflow. The percentage peak of RI corresponds to a net moisture inflow of $20-30 \mathrm{~kg} \mathrm{~m}^{-2} \mathrm{~s}^{-1}$, about $10 \mathrm{~kg} \mathrm{~m}^{-2} \mathrm{~s}^{-1}$ larger than that of SI. As expected, the distribution of NI is in between showing a near flat top between 10 and $30 \mathrm{~kg}$ $\mathrm{m}^{-2} \mathrm{~s}^{-1}$. Results from Figure 10 are in general consistent with early studies which show that the environmental moisture of the lower and middle troposhere is higher for RI cases than non-RI cases [6, 7]. However, when the intensification cases are further delineated among RI, SI, and NI, this study finds the net moisture inflow before, during, and after the intensification is not significantly higher for RI than NI and the moisture inflow of RI and NI is only significantly higher than SI after the intensification.

\subsection{Upper-Level Outflow}

4.3.1. Strength of Upper-Level Outflow. The upper-level outflow strength is defined as the area-averaged divergence over a $\left(8^{\circ} \times 8^{\circ}\right)$ box around the TC center, at $200 \mathrm{hPa}$. Figure 11(a) shows the variation of the mean upper-level outflow strength 24 hours before and after the onset of the intensification for the three intensification categories. On average, the upper-level outflow strength increases prior to the RI and NI onset and continues strengthening thereafter. In contrast, there is little variation of outflow strength for SI cases. Moreover, the outflow is strongest in RI, followed by NI. The outflow strength difference between RI and NI is statistically significant at the $90 \%$ level. SI shows the weakest outflow, with SI being statistically significant weaker than RI and NI at the $95 \%$ level.

Figure 11(b) shows the frequency distribution of the three intensification categories as a function of outflow strength. The frequency peak of RI occurs at a larger outflow strength value than NI and SI. Specifically, the frequency peak of RI is at $0.9 \times 10^{-5} \mathrm{~s}^{-1}$ while those of NI and SI are at about $0.6 \times 10^{-5} \mathrm{~s}^{-1}$. Although NI and SI have similar peak outflow strength, the frequency distribution suggests that SI occurs more frequently than NI when the outflow strength is smaller than $1.2 \times 10^{-5} \mathrm{~s}^{-1}$ and vice versa. Consistent with Figure 11(a), these results further suggest that the occurrence of RI is associated with stronger outflow strength than both NI and SI, and SI usually occurs under the environment with the weaker outflow. In other words, the three intensification categories occur under significantly different outflow strengths. These results are consistent with the previous studies that the upper-level radial outflow is much stronger for intensifying cases than nonintensifying cases 


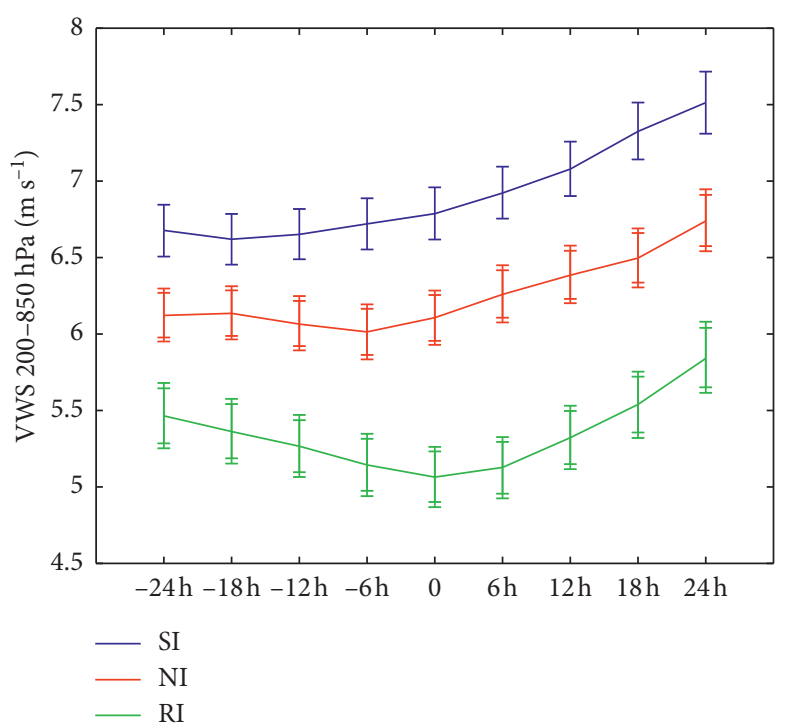

(a)

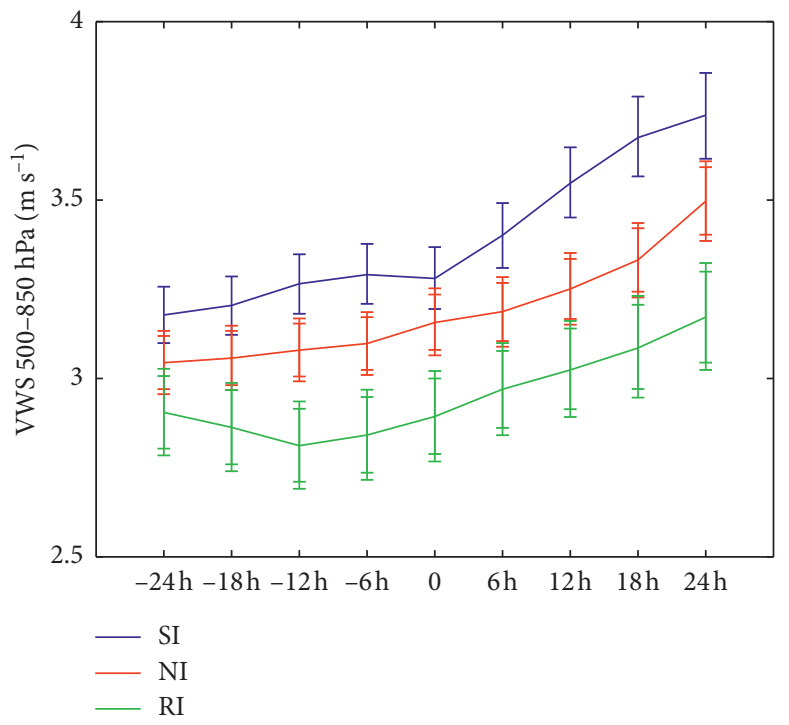

(c)

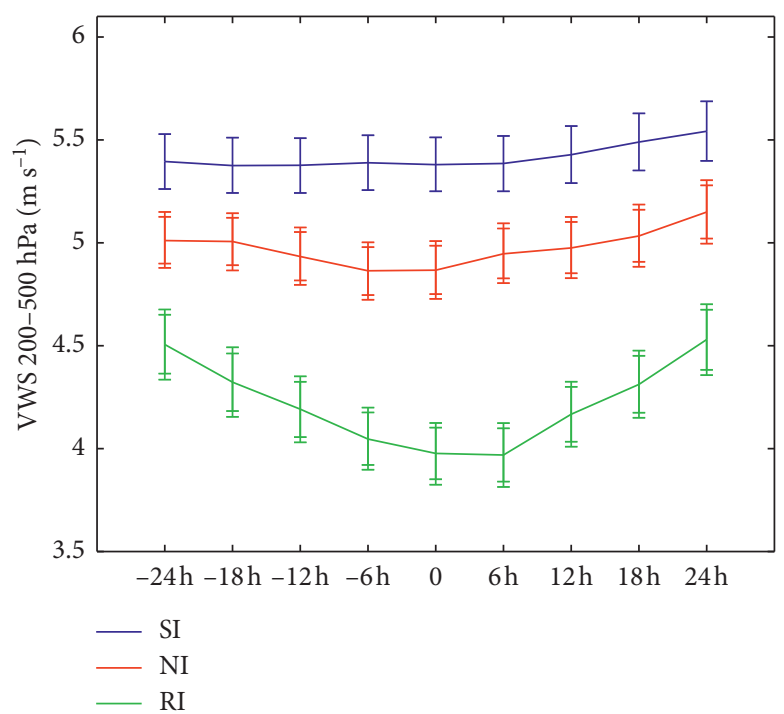

(b)

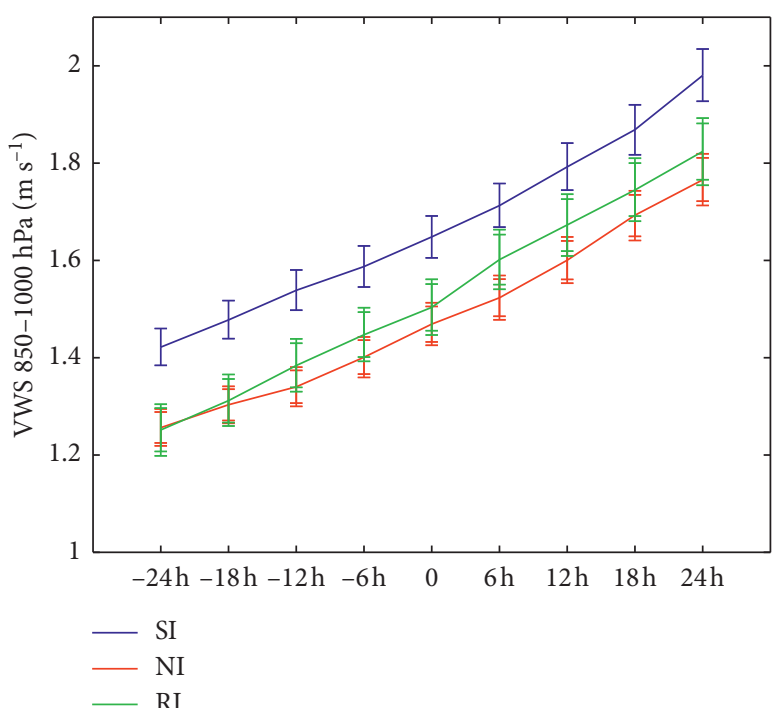

(d)

FIgURE 7: The change in environmental vertical wind shear (VWS, $\mathrm{m} \mathrm{s}^{-1}$ ): (a) deep-layer shear $\mathrm{VWS}_{200-850}$, (b) upper-mid shear VWS $200-500$, (c) mid-low shear $\mathrm{VWS}_{500-850}$, (d) low-level shear $\mathrm{VWS}_{850-1000}$ of RI (green), NI (red), and SI (blue) process. 0 of $x$-axis is the onset time of RI, and $-24 \mathrm{~h},-18 \mathrm{~h},-12 \mathrm{~h}$, and $-6 \mathrm{~h}$ are 24 hours, 18 hours, 12 hours, and 6 hours before intensification. The thick and thin error bars are the $95 \%$ and $90 \%$ confidence intervals, respectively.

[43]. But our results focus only on the intensification cases without including weakening cases and examine the association of the occurrence of difference intensification rates with the strength of the outflow.

4.3.2. Direction of Upper-Level Outflow. For each intensification category, the distributions of the occurrence probabilities in the four outflow directions (NW, SW, NE, and SE) are shown in Figure 12(a). In brief, different outflow directions favor different intensification rates. RI occurs more frequently under NW and NE outflow environments than under SW and SE outflow environments. In contrast, NI occurs more frequently under NW and SW outflow environments and occurs least frequently under a SE outflow environment. SI most likely occurs within SE outflow followed by the SW, NE, and NW outflow.

Figure 12(b) shows the variation of the mean intensification rate in the four outflow directions, which further underlines the sensitivity of the intensification rate to both the outflow direction and strength. For outflow strength greater than $8-10 \mathrm{~m} \mathrm{~s}^{-1}$, the intensification rate associated with the NW and NE outflows is higher than that with the SW and SE outflows. The intensification rate with SW outflow is the second highest, and the lowest intensification rates are under SE outflow. For the weak outflow strength $\left(6-8 \mathrm{~m} \mathrm{~s}^{-1}\right)$, intensification rates associated with the NW, SW, and NE outflows are similar and higher 


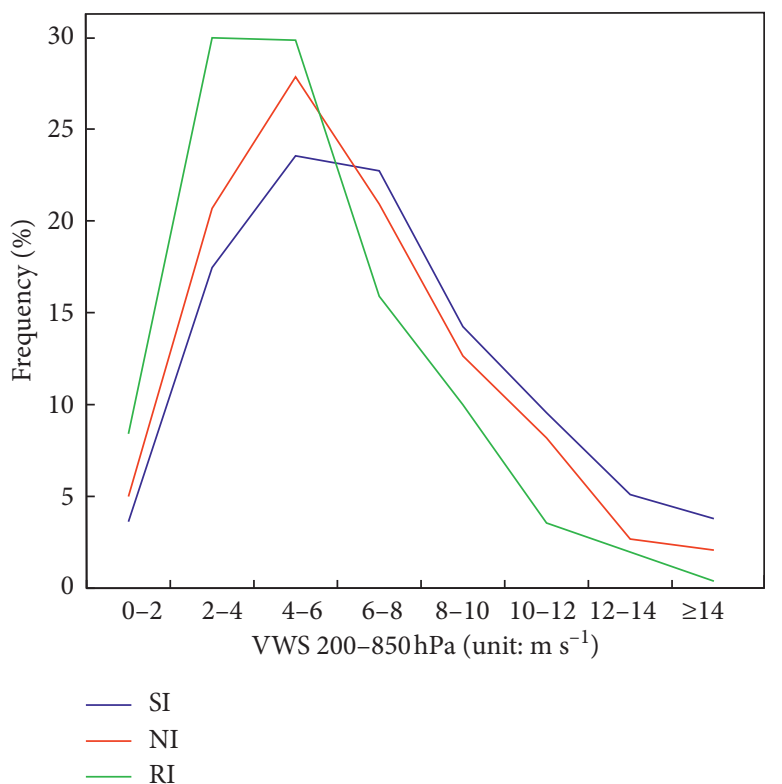

(a)

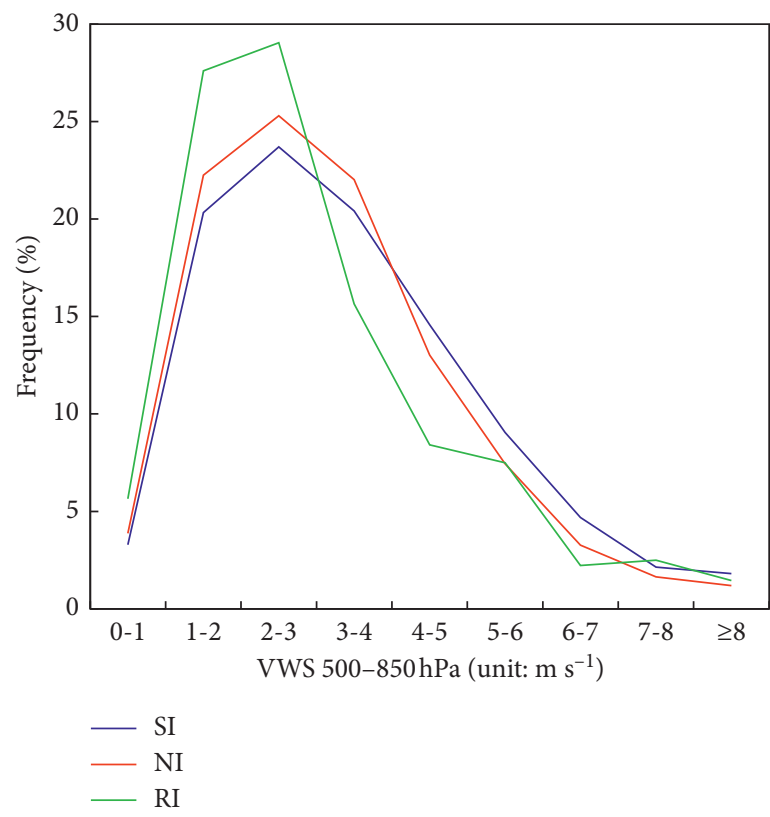

(c)

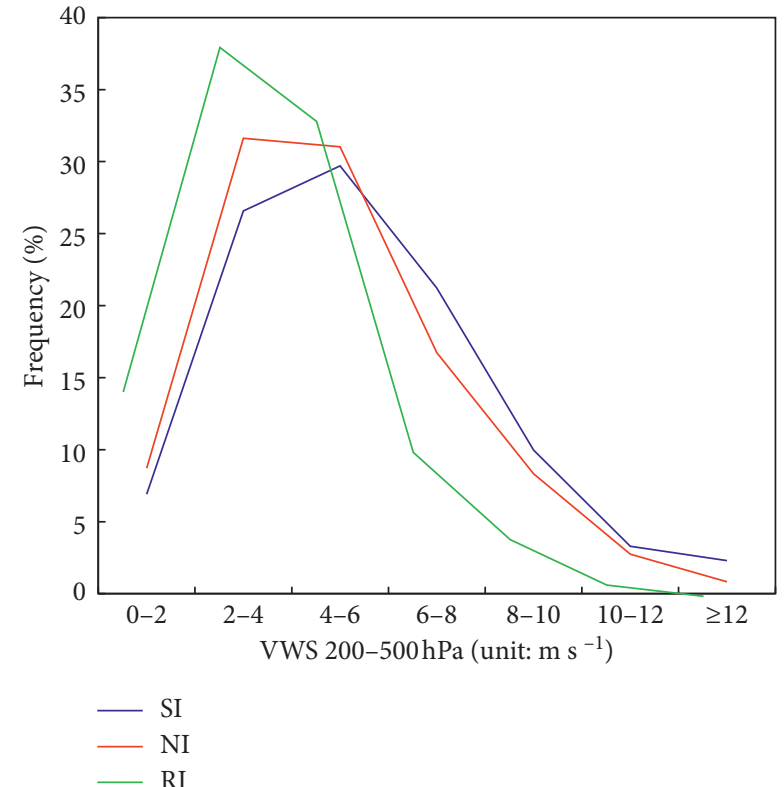

(b)

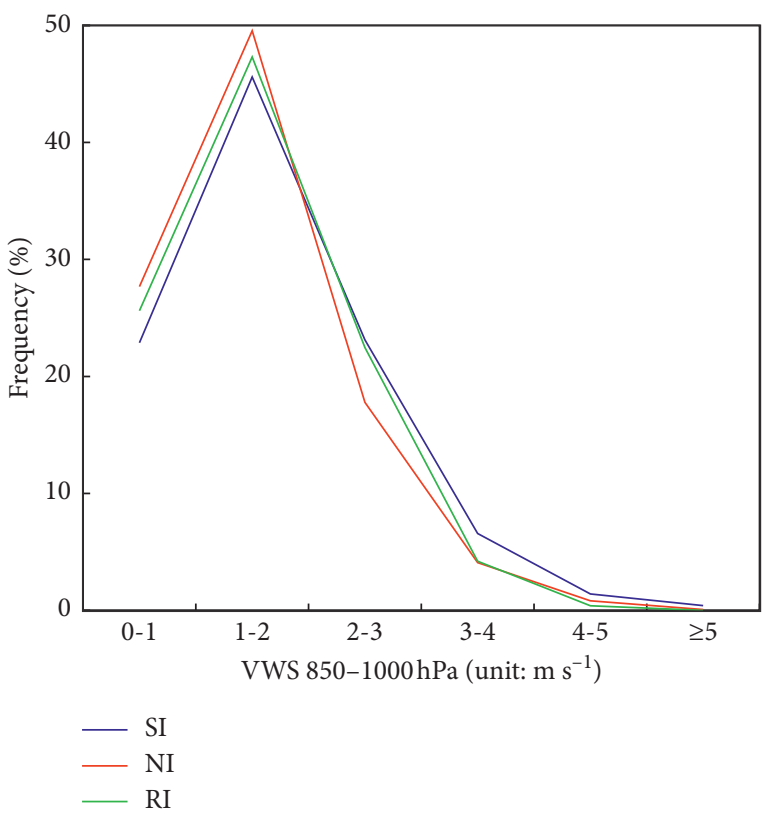

(d)

FIGURE 8: The frequency distribution of the three intensification categories (RI, NI, and SI) as a function of vertical wind shear (VWS, $\mathrm{m} \mathrm{s}^{-1}$ ): (a) deep-layer shear $\mathrm{VWS}_{200-850}$, (b) upper-mid shear $\mathrm{VWS}_{200-500}$, (c) mid-low shear $\mathrm{VWS}_{500-850}$, (d) low-level shear VWS $850-1000$.

than that of the SE outflow. In short, the larger intensification rate is associated with the NW and NE outflow and a slower intensification rate is associated with SE outflow. Additional calculation (not shown) also shows that the $\mathrm{NE}$ and NW outflow environment is often associated with a much lower mean VWS than the other two outflow directions. The SE outflow is accompanied with the largest mean VWS. In addition, however, the mean VWS decreases prior to the onset of intensification in the NE and NW outflow environment, and the mean VWS for the SE outflow increases. In brief, significant outflow differences exist between the three intensification categories. For the same outflow strength, faster intensification is most favored in the NW and NE outflows and least favored in the SE outflow. As far as the authors are aware, this study is the first published work that provides the statistic relationship between direction of outflow and intensification categories.

The relative eddy momentum flux convergence (REFC) has been used as a diagnostic to identify and/or measure the upper-level TC-environment interaction [80-83]. In this study, the REFC was calculated at $200 \mathrm{hPa}$ over $300-600 \mathrm{~km}$ radially from the TC center, for all three TC IR categories. 


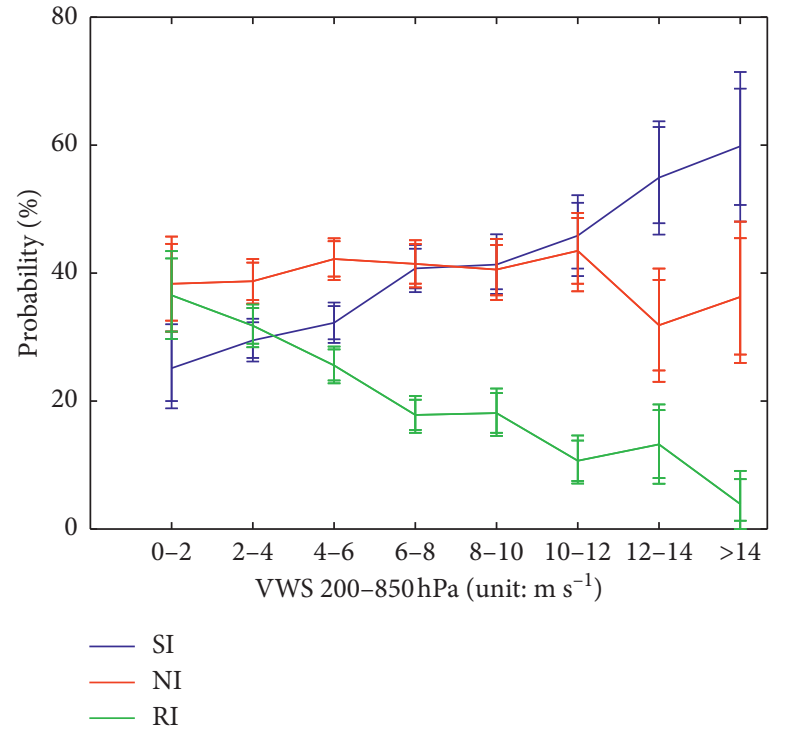

(a)

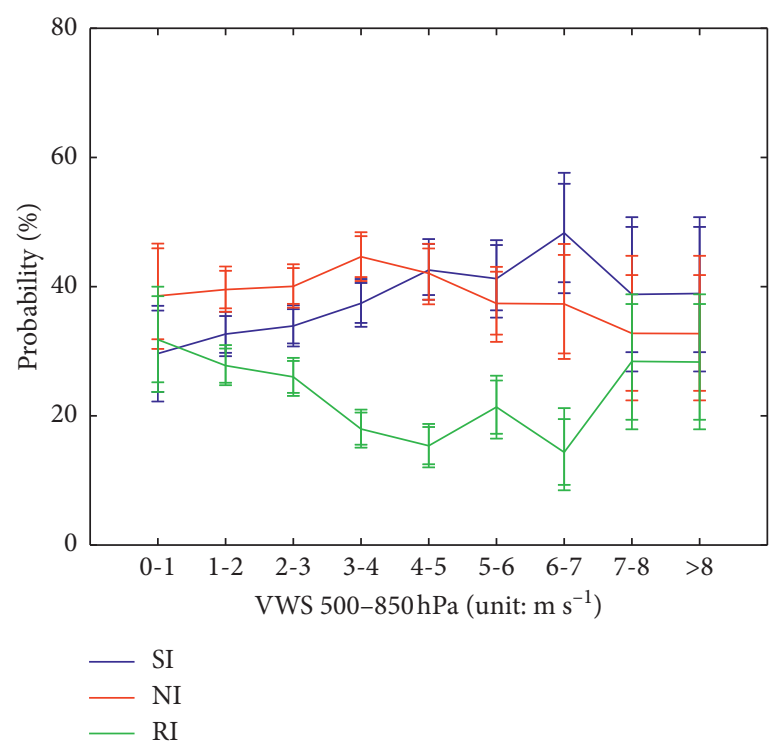

(c)

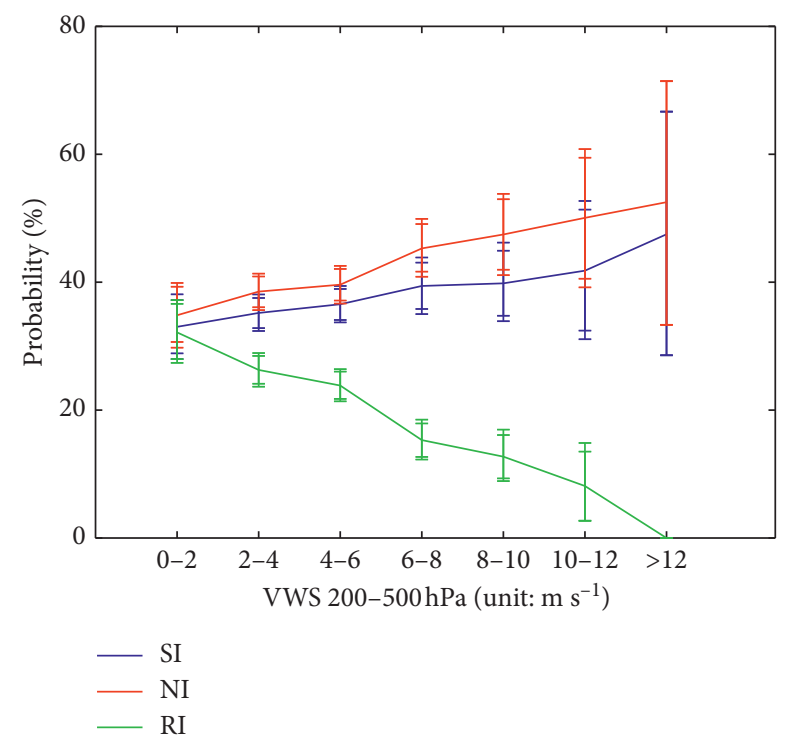

(b)

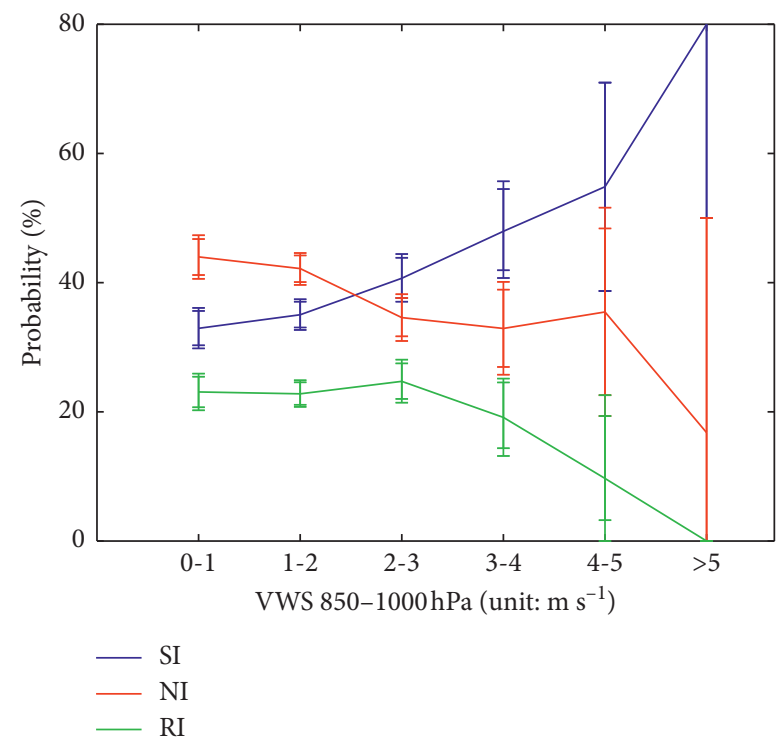

(d)

FIGURE 9: The probability distribution of the three intensity change categories (SI, blue; NI, red; and RI, green), in each VWS bin ( $\mathrm{m} \mathrm{s}^{-1}$ ): (a) deep-layer shear $\mathrm{VWS}_{200-850}$; (b) upper-mid shear $\mathrm{VWS}_{200-500}$; (c) mid-low shear VWS $\mathrm{VW0}_{500}$; (d) low-level shear $\mathrm{VWS}_{850-1000}$. The thick and thin error bars are the $95 \%$ and $90 \%$ confidence intervals, respectively.

However, consistent with Shu et al. [14], no significant differences were found between the categories (not shown).

4.4. Ocean Conditions. This section studies the statistical relationship between ocean conditions and intensification rates. Note as stated at the end of Section 2.1, the $\mathrm{OHC}$ is based on data for a shorter 9-year period (2007-2015) due to the availability of the GOADE analysis data. Figure 13 shows the variation of SST and OHC 24 hours before and after the onset of intensification. For all three intensification categories, both SST and OHC decrease during the 48-hour period. As shown in Section 3.2, most intensification cases move from warm pool toward northwest. The ocean is generally warmer in the tropical eastern and southern areas compared with the tropical western and northern NWP basin. Figure 13 also shows that SST and OHC are the highest for RI, followed by NI and then SI. Their differences are statistically significant at least at the $90 \%$ confidence interval.

Figure 14 shows the frequency distributions of the three different intensification categories, as functions of SST and OHC. For SST, the frequencies of the three intensification categories all peak at $29.5^{\circ} \mathrm{C}$ (Figure $14(\mathrm{a})$ ), but the frequenc peaks of RI and NI are higher than SI. Notably, the integrated frequency of RI is higher than NI and SI, and the integrated frequency of SI is the lowest when the SST is above $29^{\circ} \mathrm{C}$. In contrast, the integrated frequency of RI is lower 


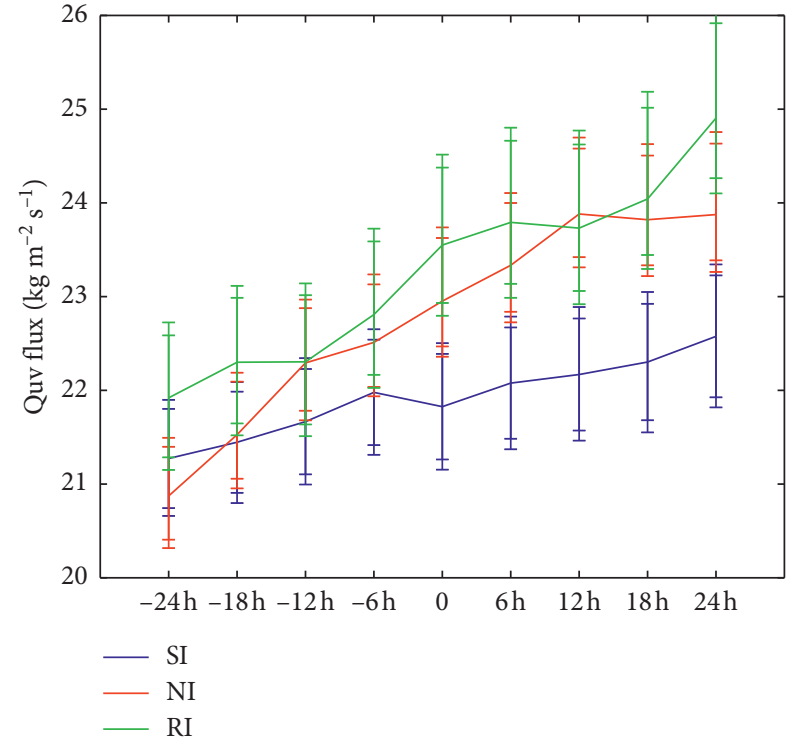

(a)

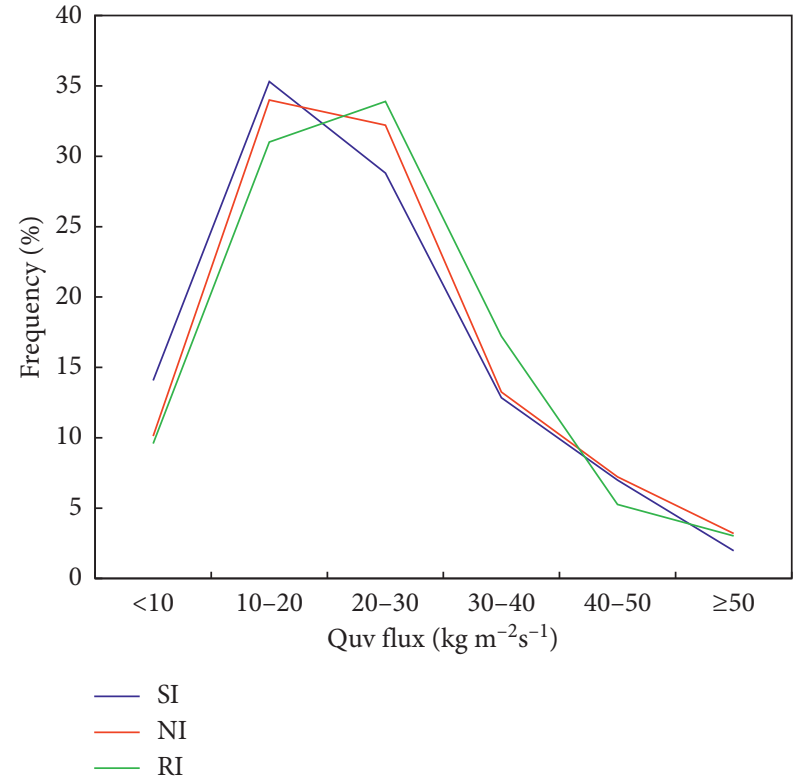

(b)

Figure 10: (a) As in Figure 7, but for net moisture inflow $\left(\mathrm{kg} \mathrm{m}^{-2} \mathrm{~s}^{-1}\right)$. (b) As in Figure 8, but for net moisture inflow.

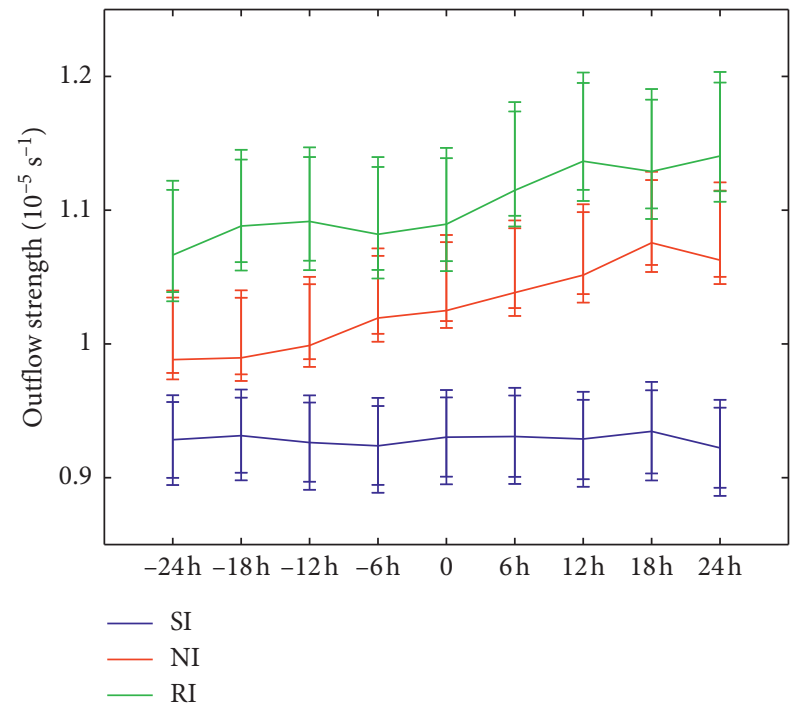

(a)

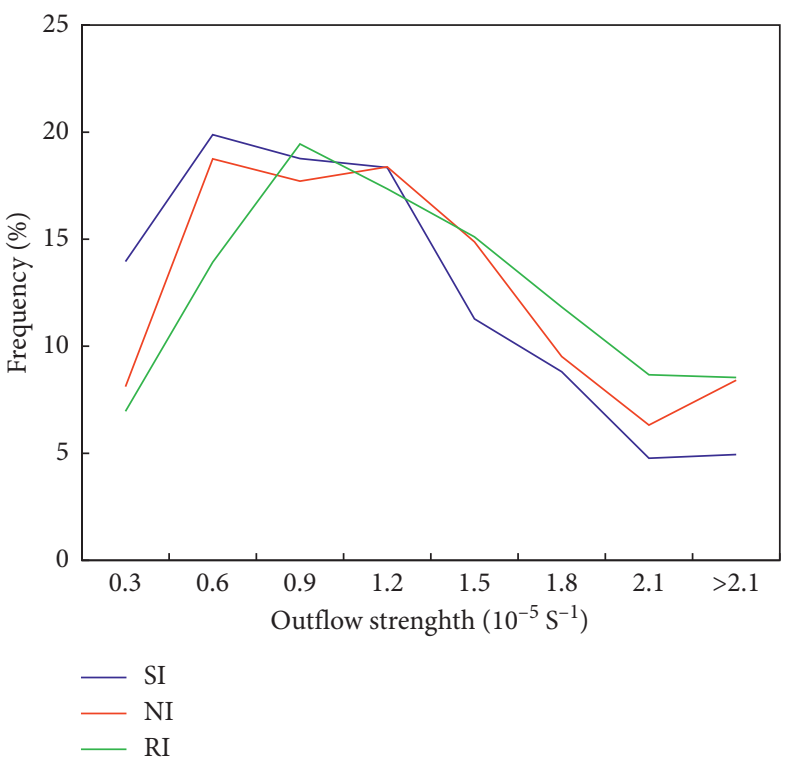

(b)

Figure 11: (a) As in Figure 7, but for the change in upper-level outflow strength $\left(10^{-5} \mathrm{~s}^{-1}\right)$ averaged over a $8^{\circ} \times 8^{\circ}$ square around TC center. (b) As in Figure 8, but for upper-level outflow strength.

than NI and SI, and the frequency of SI is the highest when the SST is below $28^{\circ} \mathrm{C}$. This result further suggests that faster intensification usually occurs over the warmer SST. In addition, Figure 14(a) shows that only a small percentage (about $5 \%$ ) of RI cases occurs with SST below $28^{\circ} \mathrm{C}$. This value is far higher than the threshold $\left(26.5^{\circ} \mathrm{C}\right)$ for TC genesis and intensification [84].

For OHC, the frequency distributions of the three intensification categories are also different (Figure 14(b)). The frequency of SI is the highest followed by NI and then RI when $\mathrm{OHC}$ is less than $40 \mathrm{~kJ} \mathrm{~cm}^{-2}$. However, the ranking is reversed when the $\mathrm{OHC}$ is above $70 \mathrm{~kJ} \mathrm{~cm}^{-2}$. More than $50 \%$ of the RI cases occur over the deeper and warmer ocean where the OHC is above $70 \mathrm{~kJ} \mathrm{~cm}^{-2}$, but less than $25 \%$ SI cases occur there. The distribution of NI lies between SI and RI. This result further suggests that faster intensification usually occurs more frequently under deeper, warmer ocean conditions.

The occurrence probabilities of the three intensification categories under the same ocean heat condition are shown in 


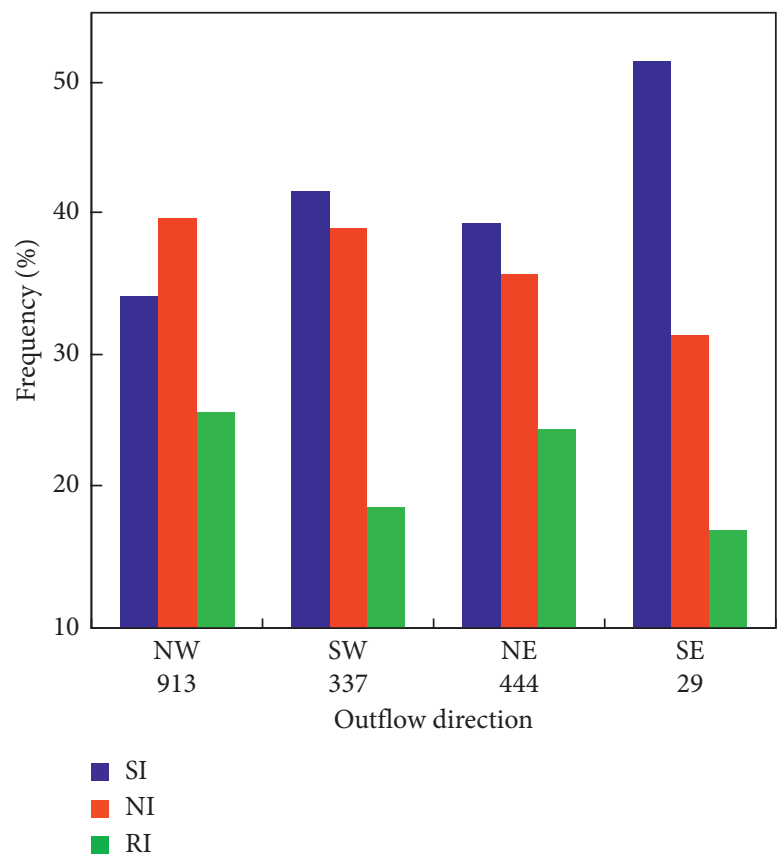

(a)

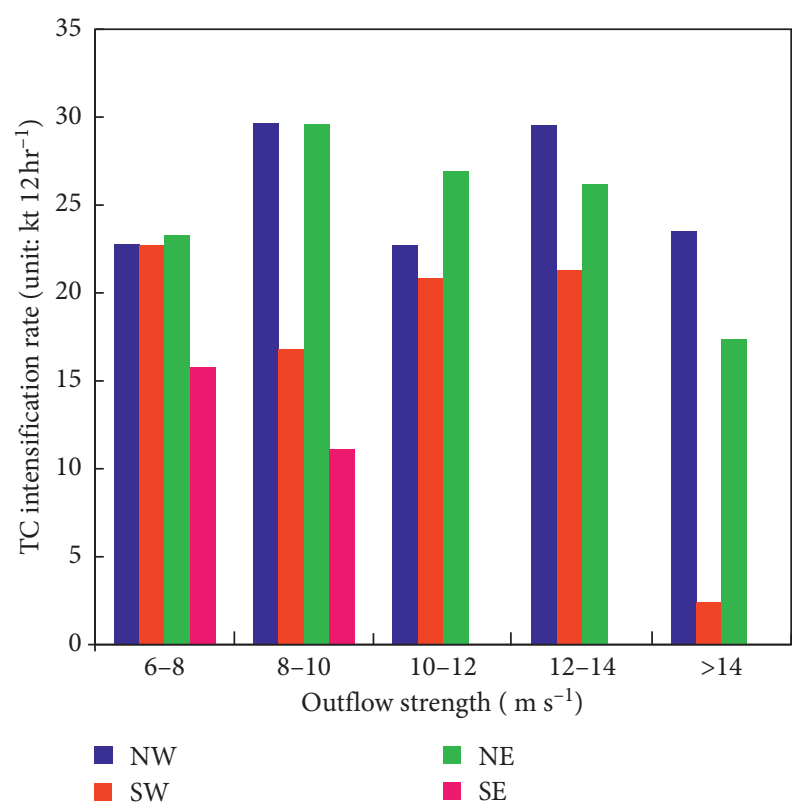

(b)

Figure 12: (a) The frequency of RI, NI, and SI in four outflow directions. The number of the below direction is the total number of the cases for each single outflow direction. (b) The average intensification rate for $12 \mathrm{hr}$ of the four outflow directions in each single outflow strength bin $\left(\mathrm{m} \mathrm{s}^{-1}\right)$. NW, NE, SE, SW is northwest, northeast, southeast, and southwest, respectively.

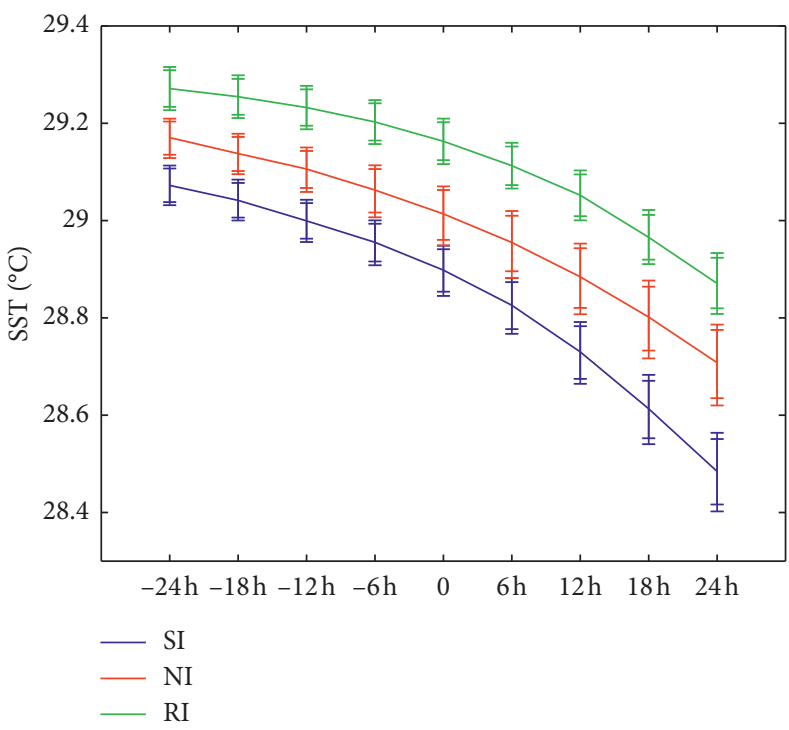

(a)

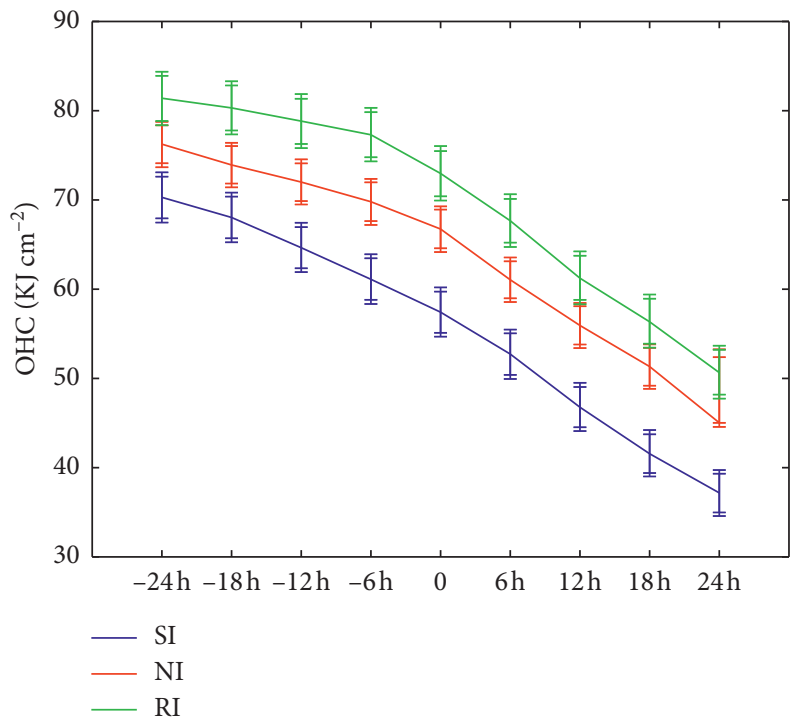

(b)

Figure 13: As in Figure 7, but for (a) SST $\left({ }^{\circ} \mathrm{C}\right)$ and (b) OHC $\left(\mathrm{kJ} \mathrm{cm}^{-2}\right)$.

Figure 15. First, the occurrence of RI is rarer than NI and SI for all SST. The occurrence probability of RI increases when the SST is above $27^{\circ} \mathrm{C}$ (Figure $15(\mathrm{a})$ ). The occurrence probability of SI decreases with an increasing SST, whereas the occurrence probability of NI does not vary with the SST. The error bars are larger when the SST is lower. Therefore, when the ocean is relatively cold, the occurrence of the three different intensification cases is more uncertain than when the ocean is warmer. The occurrence probability as a function of OHC is in general similar to SST (Figure 15(b)). But the occurrence probability of RI increases more significantly with increase of $\mathrm{OHC}$ when $\mathrm{OHC}$ is less than $90 \mathrm{~kJ}$ $\mathrm{cm}^{-2}$ and decreases slightly when $\mathrm{OHC}$ is more than $90 \mathrm{~kJ}$ $\mathrm{cm}^{-2}$.

Therefore, the warmer the ocean is, the higher occurrence probability of RI is and the lower occurrence 


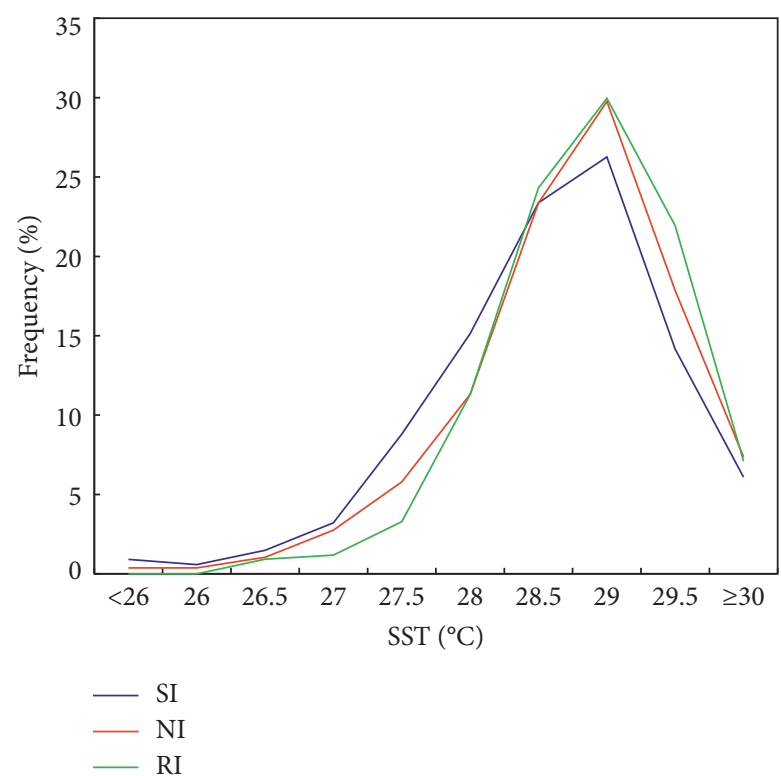

(a)

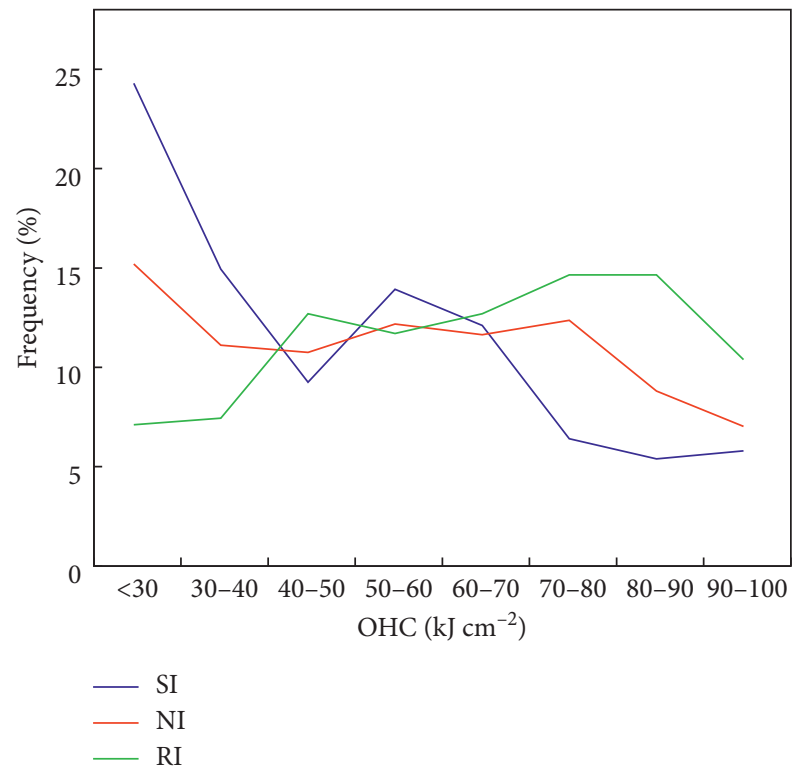

(b)

Figure 14: As in Figure 8, but for ocean heat condition. (a) SST $\left({ }^{\circ} \mathrm{C}\right)$. (b) OHC $\left(\mathrm{kJ} \mathrm{cm}^{-2}\right)$.

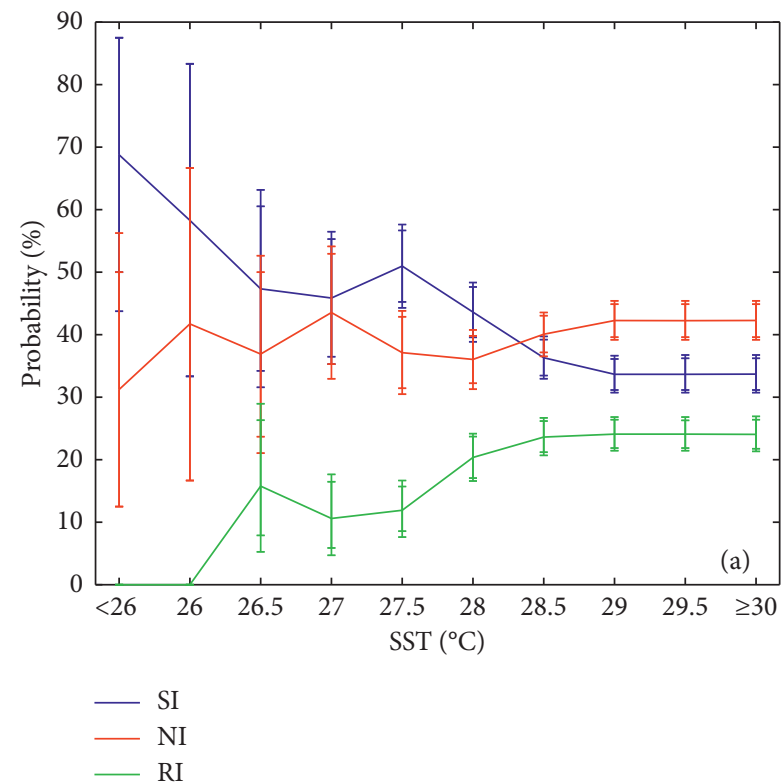

(a)

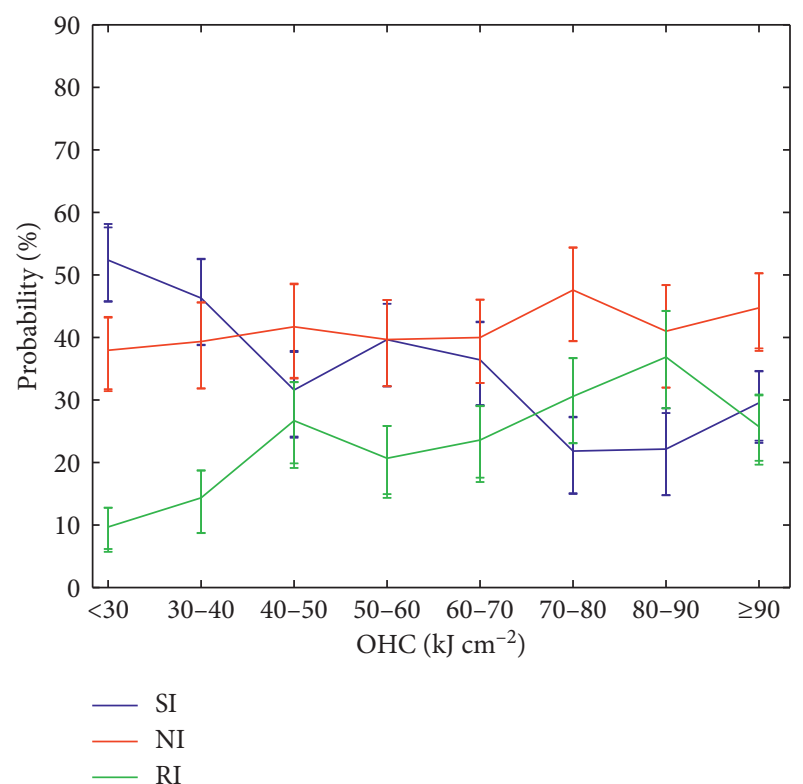

(b)

FIgure 15: : The same as in Figure 9, but for ocean heat condition: (a) SST $\left({ }^{\circ} \mathrm{C}\right)$ and (b) OHC $\left(\mathrm{kJ} \mathrm{cm}{ }^{-2}\right)$.

probability of SI is. To some extent, this result is consistent with $\mathrm{Xu}$ and Wang that shows that the maximum potential intensification rate increases with increasing SST [79]. This study however emphasizes the dependence of RI, NI, and SI on ocean conditions.

\section{Conclusions}

Using statistical approach, this study aims to address the following question: "Do significant differences in environmental factors, including atmospheric conditions and ocean heat conditions, exist between rapidly, normally, and slowly intensifying TCs in the North West Pacific Basin?" Based on the JTWC best track data, the intensification rates of all named TCs over the NWP for the 21-year period 19952005 were categorized into three intensity categories, RI, NI, and SI. The initial location and intensity, the preceding intensity change, the moving direction, the occurrence month, and the intensification duration time of TC intensification are all found to differ for RI cases compared with NI and SI cases. 
Most RI cases occur east of the Philippines and over the northern South China Sea. The mean initial intensity of RI cases is stronger than that of both NI and SI. The preceding intensity change is much faster for RI than for NI and SI, and RI cases tend to move WNW more than the NI and SI TCs. The mean intensification duration time of both RI and NI is found to be about $18 \mathrm{hr}$, whereas it is only about $14 \mathrm{hr}$ for SI. The peak active month for RI is found to be September but is August for NI and SI. Using the ERA-Interim reanalysis data and the high-resolution global ocean analysis data, the differing impacts of the large-scale environmental atmospheric and ocean heat conditions between RI, NI, and SI were examined. Overall, there are statistically significant differences between RI and NI or RI and SI responses to deep-layer $\mathrm{VWS}_{200-850}$, upper-mid VWS $\mathrm{V}_{200-500}$, and mid-low $\mathrm{VWS}_{500-850}$, upper-level outflow, SST, and OHC. The difference between RI and SI is significant for low-level $\mathrm{VWS}_{850-1000}$. For net moisture inflow, the difference between RI and SI is significant only after intensification onset. There is no statistically significant difference between RI and NI in the net moisture inflow and the low-level $\mathrm{VWS}_{850-1000}$. The differences between NI and SI significantly exist in deep-layer $\mathrm{VWS}_{200-850}$, upper-mid $\mathrm{VWS}_{200-500}$, and lowlevel $\mathrm{VWS}_{850-1000}$, upper-level outflow, and SST/OHC before, during, and after the intensification but only exist in mid-low $\mathrm{VWS}_{500-850}$ and net moisture inflow after intensification onset. These results are summarized in Table 2.

In summary, RI usually occurs under lower and decreasing VWS, enhanced and higher net moisture inflow, deeper warm ocean conditions, and stronger and increasing upper-level outflow. In contrast, SI often occurs in higher and increasing VWS, slightly increasing and lower net moisture inflow, colder ocean conditions, and weaker and static upper-level outflow. NI easily occurs in the environmental conditions that lie in between those of SI and RI. The deep-layer VWS and upper-mid layer VWS are more impactful in distinguishing the three intensification rate categories than mid-low and low-level VWS. The analysis also reveals that the direction, strength, and the increasing trend of outflow all can impact the rate of TC intensification. For example, both the NW and NE outflows favor RI, but the SE outflow is often associated with slower intensification. In addition, the differing impacts of $\mathrm{OHC}$ were found to be highly significant and more clearly distinguish the three different intensification categories than with only the SST.

This study is only limited to examine the statistical relationship between RI, NI, and SI and the individual largescale environmental factors. It is possible that favorable conditions sometimes can cancel the negative impact of unfavorable conditions on TC intensification. For example, in the situation of weak vertical wind shear and the high upperocean heat content, TC may not intensify if other environmental conditions are not favorable. In other words, the TC intensity change largely depends on the integrated impact of all the environmental factors. The results of this study indeed verify that VWS, outflow, ocean heat condition, and moisture flux can all impact TC intensification. In other words, the result of the current study also suggests that one should
TABLE 2: Significant differences between the three intensification categories.

\begin{tabular}{lccc}
\hline Environmental factors & $\mathrm{RI}$ and NI & $\mathrm{RI}$ and SI & SI and NI \\
\hline Deep-layer VWS & $* * *$ & $* * *$ & $* * *$ \\
Upper-mid VWS & $* * *$ & $* * *$ & $* * *$ \\
Mid-low VWS & $* *$ & $* * *$ & $* *$ \\
Low-level VWS & $\times$ & $* *$ & $* * *$ \\
Net moisture inflow & $\times$ & $* *$ & $* *$ \\
Upper-level outflow & $* *$ & $* * *$ & $* * *$ \\
SST & $* * *$ & $* * *$ & $* *$ \\
OHC & $* * *$ & $* * *$ & $* * *$ \\
\hline
\end{tabular}

$* * *$ and $* *$ denote significant differences with $95 \%$ and $90 \%$ confidence intervals, respectively. $\times$ shows that no significant difference exists.

consider all these environmental factors when determining and predicting the TC intensification categories. Although the focus of this paper is not to directly improve SHIPS (e.g., [64]), the results of the study suggest SHIPS may benefit from using additional predictors such as the trend of the VWS, the trend of the upper-level outflow strength, and the direction of outflow during the TC intensity forecast.

It is also found that both the strength and direction of upper-level outflow can impact TC intensification rates. Precisely how the outflow direction and how the interaction of outflow and the wind shear affect intensity intensification rates are still not clear, which will require further modeling studies. Difference of moisture conditions between the RI and NI categories is not significant. However, this does not imply that the moisture conditions are unimportant for TC intensification. To some extent, the monsoon background over NWP basin usually provides favorable moisture condition for TC intensification during an active TC season. It is also found that the occurrence probability of both RI and the mean intensification rate decreases with an increase of $Q u v$ when $Q u v$ is higher than $40 \mathrm{~kg} \mathrm{~m}^{-2} \mathrm{~s}^{-1}$ (not shown), suggesting that excessive moisture is not favorable for TC RI. In addition, satellite observations showed that the impact of moisture on TC intensity change depends on its quadrant distribution or relative location to the TC motion $[35,85]$. This study uses statistical approach to associate the three intensification categories with the environmental factors. Additional modeling studies should be planned to understand the dynamical and thermodynamical processes that explain the relationship between the large-scale environment and the three TC intensification rates.

\section{Data Availability}

The data used to support the findings of this study are available from the corresponding author upon request.

\section{Conflicts of Interest}

The authors declare that there are no conflicts of interest regarding the publication of this paper.

\section{Acknowledgments}

The research documented in this paper was supported by ONR grants N00014-14-1-0125 and N000141712111. 


\section{References}

[1] R. L. Elsberry, T. D. B. Lambert, and M. A. Boothe, "Accuracy of Atlantic and eastern North Pacific tropical cyclone intensity forecast guidance," Weather and Forecasting, vol. 22, no. 4, pp. 747-762, 2007.

[2] R. Gall, J. Franklin, F. Marks, E. N. Rappaport, and F. Toepfer, "The hurricane forecast improvement project," Bulletin of the American Meteorological Society, vol. 94, no. 1, pp. 329-343, 2013.

[3] N. Wei, J. L. McBride, X. Zhang, and Y. Duan, "Understanding biases in tropical cyclone intensity forecast error," Weather and Forecasting, vol. 33, no. 1, pp. 129-138, 2018.

[4] A. Simon, A. B. Penny, M. DeMaria et al., "A description of the real-time HFIP corrected consensus approach (HCCA) for tropical cyclone track and intensity guidance," Weather and Forecasting, vol. 33, no. 1, pp. 37-57, 2018.

[5] J. Kaplan and M. DeMaria, "Large-scale characteristics of rapidly intensifying tropical cyclones in the north Atlantic basin," Weather and Forecasting, vol. 18, no. 6, pp. 1093-1108, 2003.

[6] J. Kaplan, M. DeMaria, and J. A. Knaff, "A revised tropical cyclone rapid intensification index for the atlantic and eastern north pacific basins," Weather and Forecasting, vol. 25, no. 1, pp. 220-241, 2010.

[7] E. A. Hendricks, M. S. Peng, B. Fu, and T. Li, "Quantifying environmental control on tropical cyclone intensity change," Monthly Weather Review, vol. 138, no. 8, pp. 3243-3271, 2010.

[8] J. Xu, Y. Wang, and Z.-M. Tan, "The relationship between sea surface temperature and maximum intensification rate of tropical cyclones in the north atlantic," Journal of the Atmospheric Sciences, vol. 73, no. 12, pp. 4979-4988, 2016.

[9] J. L. McBride, "Tropical cyclone formation," in Chapter 3 of Global Perspectives on Tropical Cyclones, R. Elsberry, Ed., pp. 63-105, World Meteorological Organization, Geneva, Switzerland, 1995.

[10] E. A. Ritchie and G. J. Holland, "Large-scale patterns associated with tropical cyclogenesis in the western Pacific," Monthly Weather Review, vol. 127, no. 9, pp. 2027-2043, 1999.

[11] C. Thorncroft and K. Hodges, "African easterly wave variability and its relationship to atlantic tropical cyclone activity," Journal of Climate, vol. 14, no. 6, pp. 1166-1179, 2001.

[12] Y. Wang, Y. Rao, Z.-M. Tan, and D. Schönemann, "A statistical analysis of the effects of vertical wind shear on tropical cyclone intensity change over the western north pacific," Monthly Weather Review, vol. 143, no. 9, pp. 3434-3453, 2015.

[13] R. Rios-Berrios and R. D. Torn, "Climatological analysis of tropical cyclone intensity changes under moderate vertical wind shear," Monthly Weather Review, vol. 145, no. 5, pp. 1717-1738, 2017.

[14] S. Shu, J. Ming, and P. Chi, "Large-scale characteristics and probability of rapidly intensifying tropical cyclones in the western north Pacific basin," Weather and Forecasting, vol. 27, no. 2, pp. 411-423, 2012.

[15] T. A. Cram, J. Persing, M. T. Montgomery, and S. A. Braun, "A Lagrangian trajectory view on transport and mixing processes between the eye, eyewall, and environment using a high-resolution simulation of hurricane bonnie (1998)," Journal of the Atmospheric Sciences, vol. 64, no. 6, pp. 18351856, 2007.

[16] M. DeMaria and J. Kaplan, "An updated statistical hurricane intensity prediction scheme (SHIPS) for the Atlantic and eastern North Pacific basins," Weather and Forecasting, vol. 14, no. 3, pp. 326-337, 1999.

[17] M. Riemer, M. T. Montgomery, and M. E. Nicholls, "A new paradigm for intensity modification of tropical cyclones: thermodynamic impact of vertical wind shear on the inflow layer," Atmospheric Chemistry and Physics, vol. 10, no. 7, pp. 3163-3188, 2010.

[18] Z. Zeng, Y. Wang, and C.-C. Wu, "Environmental dynamical control of tropical cyclone intensity-an observational study," Monthly Weather Review, vol. 135, no. 1, pp. 38-59, 2007.

[19] J. A. Knaff, C. R. Sampson, and M. DeMaria, "An operational statistical typhoon intensity prediction scheme for the western north pacific," Weather and Forecasting, vol. 20, no. 4, pp. 688-699, 2005.

[20] F. Zhang and D. Tao, "Effects of vertical wind shear on the predictability of tropical cyclones," Journal of the Atmospheric Sciences, vol. 70, no. 3, pp. 975-983, 2013.

[21] D. Tao and F. Zhang, "Effect of environmental shear, seasurface temperature, and ambient moisture on the formation and predictability of tropical cyclones: an ensemble-mean perspective," Journal of Advances in Modeling Earth Systems, vol. 6, no. 2, pp. 384-404, 2014.

[22] E. B. Munsell, F. Zhang, J. A. Sippel, S. A. Braun, and Y. Weng, "Dynamics and predictability of the intensification of hurricane edouard (2014)," Journal of the Atmospheric Sciences, vol. 74, no. 2, pp. 573-595, 2017.

[23] S. Shu, Y. Wang, and L. Bai, "Insight into the role of lowerlayer vertical wind shear in tropical cyclone intensification over the western North Pacific," Acta Meteorologica Sinica, vol. 27, no. 3, pp. 356-363, 2013.

[24] P. M. Finocchio, S. J. Majumdar, D. S. Nolan, and M. Iskandarani, "Idealized tropical cyclone responses to the height and depth of environmental vertical wind shear," Monthly Weather Review, vol. 144, no. 6, pp. 2155-2175, 2016.

[25] M. J. Onderlinde and D. S. Nolan, "Environmental helicity and its effects on development and intensification of tropical cyclones," Journal of the Atmospheric Sciences, vol. 71, no. 11, pp. 4308-4320, 2014.

[26] C. S. Velden and L. M. Leslie, "The basic relationship between tropical cyclone intensity and the depth of the environmental steering layer in the Australian region," Weather and Forecasting, vol. 6, no. 2, pp. 244-253, 1991.

[27] Z. Zeng, Y. Wang, and L.-S. Chen, "A statistical analysis of vertical shear effect on tropical cyclone intensity change in the North Atlantic," Geophysical Research Letters, vol. 37, no. 2, Article ID L02802, 2010.

[28] C. S. Velden and J. Sears, "Computing deep-tropospheric vertical wind shear analyses for tropical cyclone applications: does the methodology matter?," Weather and Forecasting, vol. 29, no. 5, pp. 1169-1180, 2014.

[29] P. M. Finocchio and S. J. Majumdar, "A statistical perspective on wind profiles and vertical wind shear in tropical cyclone environments of the northern Hemisphere," Monthly Weather Review, vol. 145, no. 1, pp. 361-378, 2017.

[30] K. Emanuel, C. DesAutels, C. Holloway, and R. Korty, "Environmental control of tropical cyclone intensity," Journal of the Atmospheric Sciences, vol. 61, no. 7, pp. 843-858, 2004.

[31] X. Lu, K. K. W. Cheung, and Y. Duan, "Numerical study on the formation of typhoon ketsana (2003). Part I: roles of the mesoscale convective systems," Monthly Weather Review, vol. 140, no. 1, pp. 100-120, 2012.

[32] S. A. Braun, J. A. Sippel, and D. S. Nolan, "The impact of dry midlevel air on hurricane intensity in idealized simulations 
with no mean flow," Journal of the Atmospheric Sciences, vol. 69, no. 1, pp. 236-257, 2012.

[33] Y. Wang, "How do outer spiral rainbands affect tropical cyclone structure and intensity?," Journal of the Atmospheric Sciences, vol. 66, no. 5, pp. 1250-1273, 2009.

[34] K. A. Hill and G. M. Lackmann, "Influence of environmental humidity on tropical cyclone size," Monthly Weather Review, vol. 137, no. 10, pp. 3294-3315, 2009.

[35] L. Wu, H. Su, R. G. Fovell et al., "Impact of environmental moisture on tropical cyclone intensification," Atmospheric Chemistry and Physics Discussions, vol. 15, no. 24, pp. 16111-16139, 2015.

[36] P. G. Black and R. A. Anthes, "On the asymmetric structure of the tropical cyclone outflow layer," Journal of the Atmospheric Sciences, vol. 28, no. 8, pp. 1348-1366, 1971.

[37] R. T. Merrill, "Environmental influences on hurricane intensification," Journal of the Atmospheric Sciences, vol. 45, no. 11, pp. 1678-1687, 1988.

[38] J. Molinari, P. Duran, and D. Vollaro, "Low Richardson number in the tropical cyclone outflow layer," Journal of the Atmospheric Sciences, vol. 71, no. 9, pp. 3164-3179, 2014.

[39] P. Duran and J. Molinari, "Upper-tropospheric low Richardson number in tropical cyclones: sensitivity to cyclone intensity and the diurnal cycle," Journal of the Atmospheric Sciences, vol. 73, no. 2, pp. 545-554, 2016.

[40] G. J. Holland and R. T. Merrill, "On the dynamics of tropical cyclone structural changes," Quarterly Journal of the Royal Meteorological Society, vol. 110, no. 465, pp. 723-745, 1984.

[41] E. D. Rappin, M. C. Morgan, and G. J. Tripoli, "The impact of outflow environment on tropical cyclone intensification and structure," Journal of the Atmospheric Sciences, vol. 68, no. 2, pp. 177-194, 2011.

[42] B. S. Barrett, E. R. Sanabia, S. C. Reynolds, J. K. Stapleton, and A. L. Borrego, "Evolution of the upper-tropospheric outflow in hurricanes Iselle and Julio (2014) in the navy global environmental model (NAVGEM) analyses and in satellite and dropsonde observations," Journal of Geophysical Research: Atmospheres, vol. 13, no. 10, pp. 273-286, 2016.

[43] W. A. Komaromi and J. D. Doyle, "Tropical cyclone outflow and warm core structure as revealed by HS3 dropsonde data," Monthly Weather Review, vol. 145, no. 4, pp. 1339-1359, 2017.

[44] L. Chen and W. M. Gray, "Global view of the upper level outflow patterns associated with tropical cyclone intensity changes during FGGE," Colorado State University Dept. of Atmospheric Science Paper 392, Colorado State University, Fort Collins, Colorado, p. 126, 1985.

[45] J. Molinari and D. Vollaro, "External influences on hurricane intensity. Part I: outflow layer eddy angular momentum fluxes," Journal of the Atmospheric Sciences, vol. 46, no. 8, pp. 1093-1105, 1989.

[46] R. L. Pfeffer and M. Challa, "The role of environmental asymmetries in Atlantic hurricane formation," Journal of the Atmospheric Sciences, vol. 49, no. 12, pp. 1051-1059, 1992.

[47] C.-C. Wu and K. A. Emanuel, "On hurricane outflow structure," Journal of the Atmospheric Sciences, vol. 51, no. 13, pp. 1995-2003, 1994.

[48] W. M. Frank and E. A. Ritchie, "Effects of environmental flow upon tropical cyclone structure," Monthly Weather Review, vol. 127, no. 9, pp. 2044-2061, 1999.

[49] J. Feng and X. Wang, "Impact of assimilating upper-level dropsonde observations collected during the TCI field campaign on the prediction of intensity and structure of Hurricane Patricia (2015)," Monthly Weather Review, vol. 147, no. 8, pp. 3069-3089, 2019, In press.
[50] L. F. Bosart, C. S. Velden, W. E. Bracken, J. Molinari, and P. G. Black, "Environmental influences on the rapid intensification of hurricane opal (1995) over the gulf of Mexico," Monthly Weather Review, vol. 128, no. 2, pp. 322-352, 2000.

[51] J. C. Sadler, "A role of the tropical upper tropospheric trough in early season typhoon development," Monthly Weather Review, vol. 104, no. 10, pp. 1266-1278, 1976.

[52] R. T. Merrill and C. S. Velden, "A three-dimensional analysis of the outflow layer of Supertyphoon Flo (1990)," Monthly Weather Review, vol. 124, no. 1, pp. 47-63, 1996.

[53] J. D. Ventham and B. Wang, "Large-scale flow patterns and their influence on the intensification rates of western North Pacific tropical storms," Monthly Weather Review, vol. 135, no. 4, pp. 1110-1127, 2007.

[54] H. R. Byers, General Meteorology, McGraw-Hill, New York, USA, 1944.

[55] B. I. Miller, "On the maximum intensity of hurricanes," Journal of Meteorology, vol. 15, no. 2, pp. 184-195, 1958.

[56] A. Wada, "Reexamination of tropical cyclone heat potential in the western north pacific," Journal of Geophysical Research: Atmospheres, vol. 121, no. 12, pp. 6723-6744, 2016.

[57] A. Wada, "Verification of tropical cyclone heat potential for tropical cyclone intensity forecasting in the Western North Pacific," Journal of Oceanography, vol. 71, no. 4, pp. 373-387, 2015.

[58] J. S. Malkus and H. Riehl, "On the dynamics and energy transformations in steady-state hurricanes," Tellus, vol. 12, no. 1, pp. 1-20, 1960.

[59] L. K. Shay, G. J. Goni, and P. G. Black, "Effects of a warm oceanic feature on hurricane opal," Monthly Weather Review, vol. 128, no. 5, pp. 1366-1383, 2000.

[60] A. Lowag, M. L. Black, and M. D. Eastin, "Structural and intensity changes of hurricane bret (1999) - part I: environmental influences," Monthly Weather Review, vol. 136, no. 11, pp. 4320-4333, 2008.

[61] J. C. L. Chan, Y. Duan, and L. K. Shay, "Tropical cyclone intensity change from a simple ocean-atmosphere coupled model," Journal of the Atmospheric Sciences, vol. 58, no. 2, pp. 154-172, 2001.

[62] P. C. Meyers, L. K. Shay, and J. K. Brewster, “Development and analysis of the systematically merged Atlantic regional temperature and salinity climatology for oceanic heat content estimates," Journal of Atmospheric and Oceanic Technology, vol. 31, no. 1, pp. 131-149, 2014.

[63] M. Mainelli, M. DeMaria, L. K. Shay, and G. Goni, “Application of oceanic heat content estimation to operational forecasting of recent atlantic category 5 hurricanes," Weather and Forecasting, vol. 23, no. 1, pp. 3-16, 2008.

[64] M. Yamaguchi, H. Owada, U. Shimada et al., "Tropical cyclone intensity prediction in the western North Pacific basin using SHIPS and JMA/GSM," SOLA, vol. 14, pp. 138-143, 2018.

[65] D. P. Dee, S. Uppala, A. J. Simmons et al., "The ERA Interim reanalysis: configuration and performance of the data assimilation system," Journal of the Royal Meteorological Society, vol. 137, no. 656, pp. 533-597, 2011.

[66] N. Lin, R. Jing, Y. Wang, E. Yonekura, J. Fan, and L. Xue, “A statistical investigation of the dependence of tropical cyclone intensity change on the surrounding environment," Monthly Weather Review, vol. 145, no. 7, pp. 2813-2831, 2017.

[67] B. A. Schenkel and R. E. Hart, "An examination of tropical cyclone position, intensity, and intensity life cycle within atmospheric reanalysis datasets," Journal of Climate, vol. 25, no. 10, pp. 3453-3475, 2012. 
[68] K. Hodges, A. Cobb, and P. L. Vidale, "How well Are tropical cyclones represented in reanalysis datasets?," Journal of Climate, vol. 30, no. 14, pp. 5243-5264, 2017.

[69] M. J. Bell, A. Schiller, P. Y. L. Traon, N. R. Smith, E. Dombrowsky, and K. Wilmer-Becker, "An introduction to GODAE ocean view," Journal of Operational Oceanography, vol. 8, no. 1, pp. 2-11, 2015.

[70] B. Huang, Y. Xue, D. Zhang, A. Kumar, and M. J. McPhaden, "The NCEP GODAS ocean analysis of the tropical pacific mixed layer heat budget on seasonal to interannual time scales," Journal of Climate, vol. 23, no. 18, pp. 4901-4925, 2010.

[71] L. N. Bai and Y. Wang, "Effect of vertical wind shear on tropical cyclone intensity change," Journal of Tropical Meteorology, vol. 22, no. 1, pp. 11-18, 2016.

[72] M. W. Buckley, R. M. Ponte, G. Forget, and P. Heimbach, "Low-frequency SST and upper-ocean heat content variability in the North Atlantic," Journal of Climate, vol. 27, no. 13, pp. 4996-5018, 2014.

[73] I.-F. Pun, I.-I. Lin, and M.-H. Lo, "Recent increase in high tropical cyclone heat potential area in the Western North Pacific Ocean," Geophysical Research Letters, vol. 40, no. 17, pp. 4680-4684, 2013.

[74] P. Hall and J. D. Hart, "Bootstrap test for difference between means in nonparametric regression," Journal of the American Statistical Association, vol. 85, no. 412, pp. 1039-1049, 1990.

[75] X. Wang and C. H. Bishop, "Improvement of ensemble reliability with a new dressing kernel," Quarterly Journal of the Royal Meteorological Society, vol. 131, no. 607, pp. 965-986, 2005.

[76] T. M. Hamill, J. S. Whitaker, M. Fiorino, and S. G. Benjamin, "Global ensemble predictions of 2009's tropical cyclones initialized with an ensemble Kalman filter," Monthly Weather Review, vol. 139, no. 2, pp. 668-688, 2011.

[77] Q. Li, P. Xu, X. Wang et al., "An operational statistical scheme for tropical cyclone induced wind gust forecasts," Weather and Forecasting, vol. 31, no. 6, pp. 1817-1832, 2016.

[78] Y. Wang and C.-C. Wu, "Current understanding of tropical cyclone structure and intensity changes - A review," Meteorology and Atmospheric Physics, vol. 87, no. 4, pp. 257-278, 2004.

[79] J. Xu and Y. Wang, "Dependence of tropical cyclone intensification rate on sea surface temperature, storm intensity, and size in the western north pacific," Weather and Forecasting, vol. 33, no. 2, pp. 523-537, 2018.

[80] M. DeMaria, J. Kaplan, and J.-J. Baik, "Upper-level eddy angular momentum fluxes and tropical cyclone intensity change," Journal of the Atmospheric Sciences, vol. 50, no. 8, pp. 1133-1147, 1993.

[81] D. Hanley, J. Molinari, and D. Keyser, "A composite study of the interactions between tropical cyclones and upper-tropospheric troughs," Monthly Weather Review, vol. 129, no. 10, pp. 2570-2584, 2001.

[82] H. Yu and H. J. Kwon, "Effect of TC-trough interaction on the intensity change of two typhoons," Weather and Forecasting, vol. 20, no. 2, pp. 199-211, 2005.

[83] X. Chen, Y. Wang, and K. Zhao, "Synoptic flow patterns and large-scale characteristics associated with rapidly intensifying tropical cyclones in the South China sea," Monthly Weather Review, vol. 143, no. 1, pp. 64-87, 2015.

[84] W. M. Gray, "Global view of the origin of tropical disturbances and storms," Monthly Weather Review, vol. 96, no. 10, pp. 669-700, 1968.
[85] S. Shu and L. Wu, "Analysis of the influence of Saharan air layer on tropical cyclone intensity using AIRS/aqua data," Geophysical Research Letters, vol. 36, no. 9, 2009. 

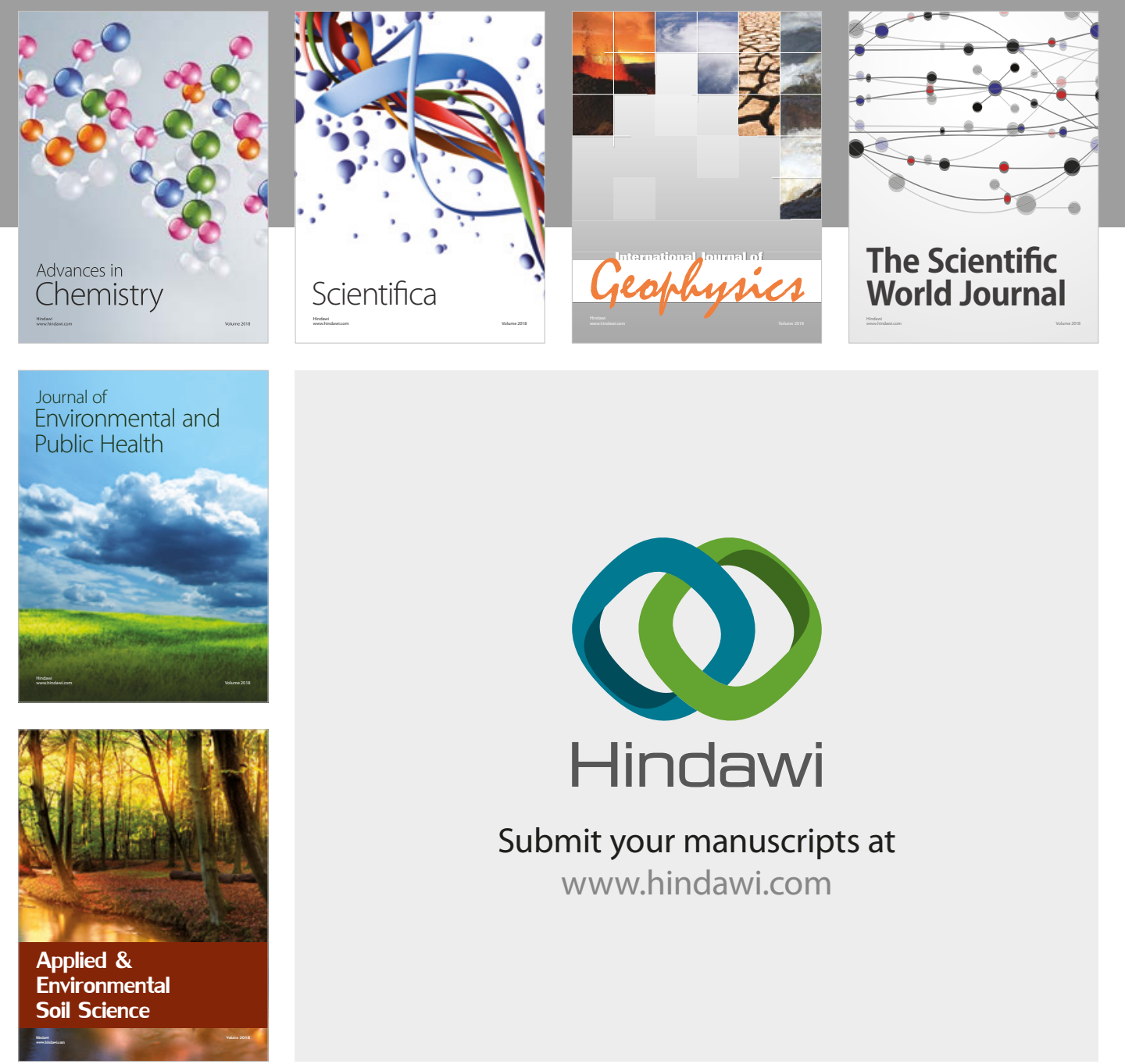

The Scientific

\section{World Journal}
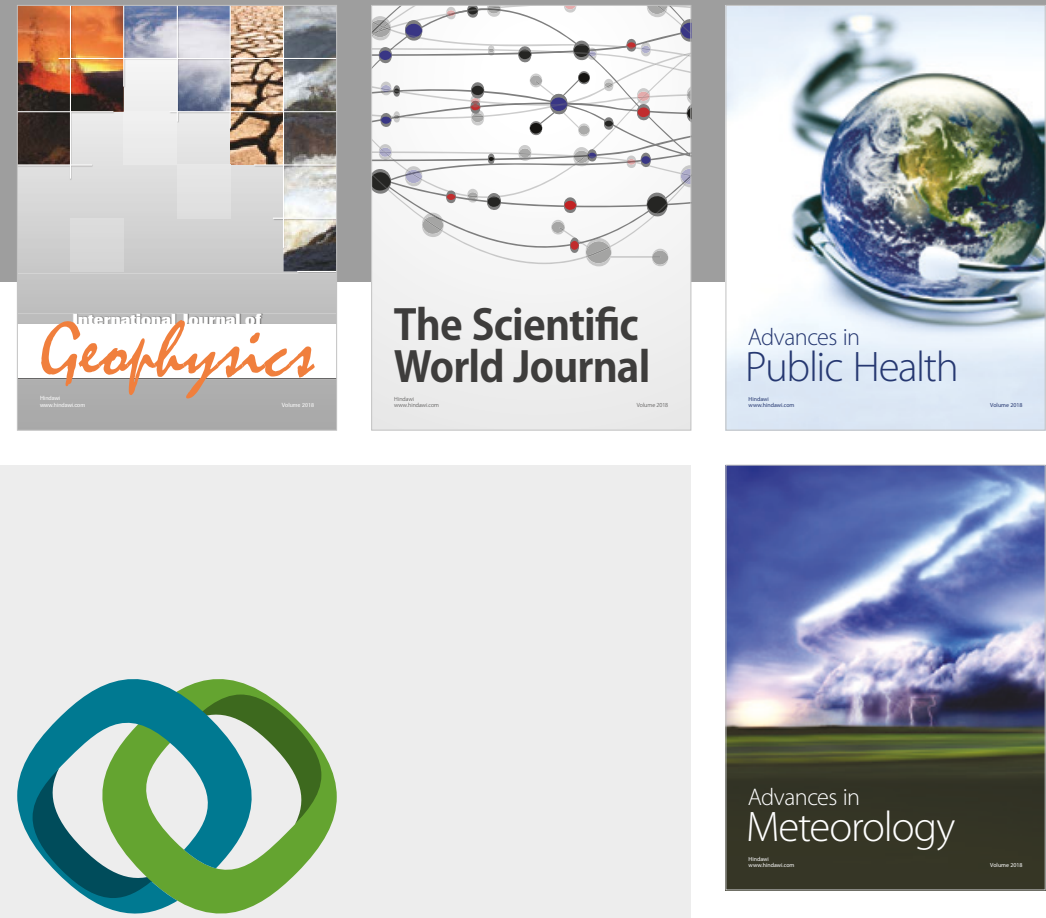

Advan

Public Health

\section{Hindawi}

Submit your manuscripts at

www.hindawi.com
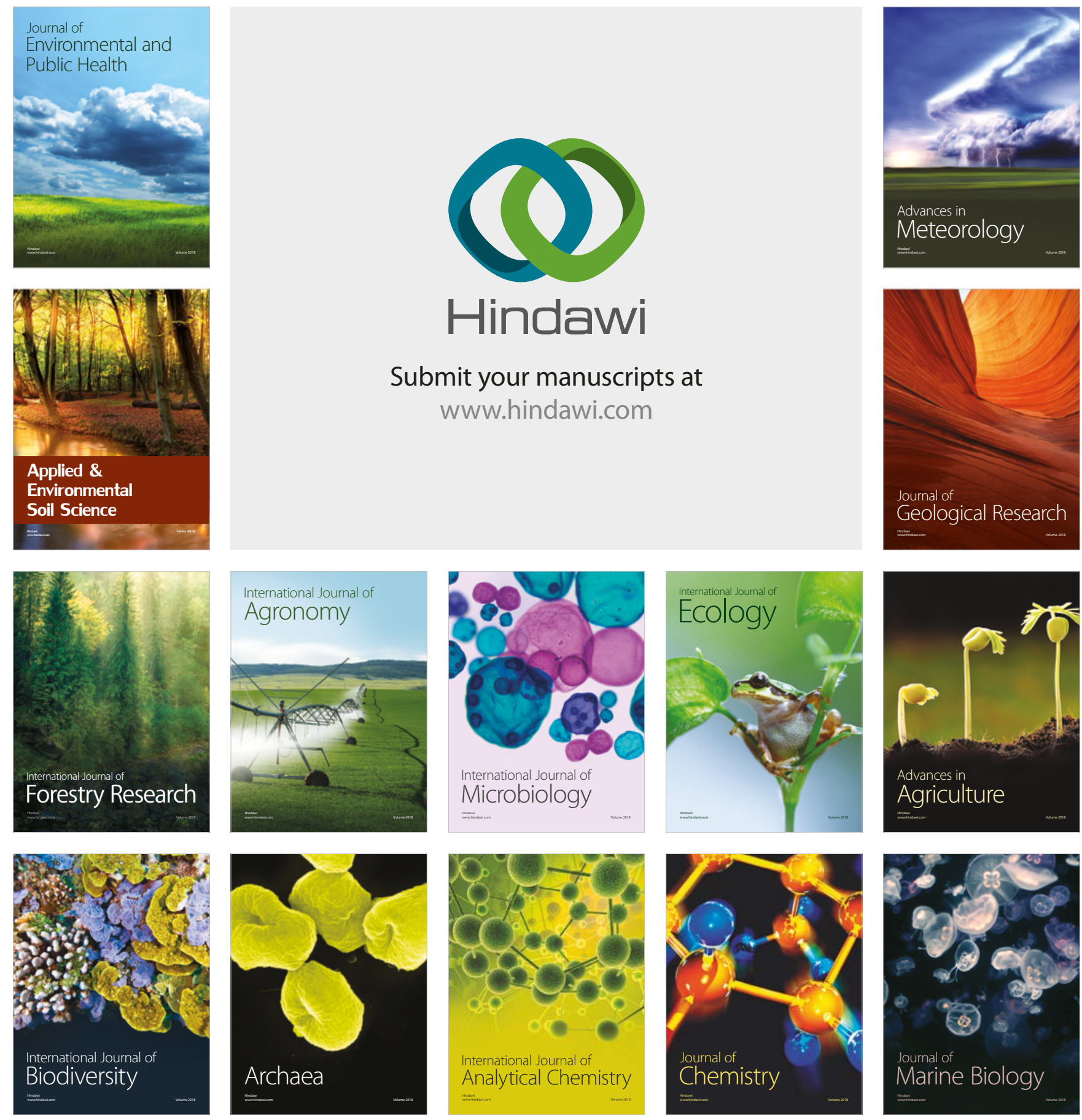